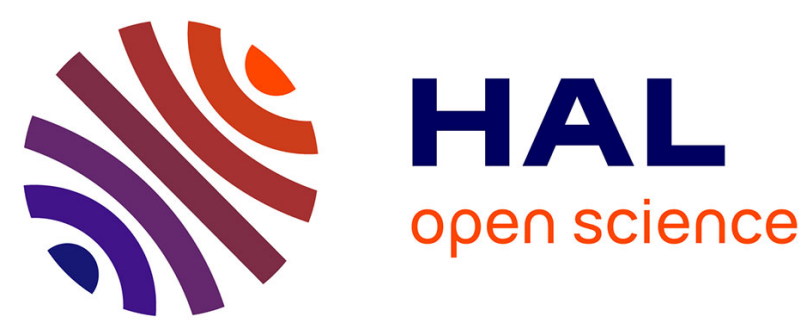

\title{
Gender empowerment as an enforcer of individuals' choice between education and fertility: Evidence from 19th century France
}

Claude Diebolt, Tapas Mishra, Faustine Perrin

\section{To cite this version:}

Claude Diebolt, Tapas Mishra, Faustine Perrin. Gender empowerment as an enforcer of individuals' choice between education and fertility: Evidence from 19th century France. Journal of Economic Behavior and Organization, 2021, 188, pp.408-438. 10.1016/j.jebo.2021.05.011 . hal-03345562

\author{
HAL Id: hal-03345562 \\ https://hal.science/hal-03345562
}

Submitted on 15 Sep 2021

HAL is a multi-disciplinary open access archive for the deposit and dissemination of scientific research documents, whether they are published or not. The documents may come from teaching and research institutions in France or abroad, or from public or private research centers.
L'archive ouverte pluridisciplinaire HAL, est destinée au dépôt et à la diffusion de documents scientifiques de niveau recherche, publiés ou non, émanant des établissements d'enseignement et de recherche français ou étrangers, des laboratoires publics ou privés. 


\section{AFC

\section{WORKING PAPERS}

\section{Nr. 12, 2019}

Gender Equality as an Enforcer of Individuals' Choice between

Education and Fertility:

Evidence from 19th Century France

Claude Diebolt, Tapas Mishra,

Faustine Perrin 


\title{
Gender Equality as an Enforcer of Individuals' Choice between Education and Fertility: Evidence from $19^{\text {th }}$ Century France
}

\author{
Claude Diebolt, Tapas Mishra and Faustine Perrin ${ }^{*}$
}

\begin{abstract}
Recent theoretical developments of growth models, especially on unified theories of growth, suggest that the child quantity-quality trade-off has been a central element of the transition from Malthusian stagnation to sustained growth. Using a unique census-based dataset, this article explores the role of gender on the trade-off between education and fertility across 86 French counties during the nineteenth century, as an empirical extension of Diebolt and Perrin (2013, 2019a). We first test the existence of the child quantity-quality trade-off in 1851 . Second, we explore the long-run effect of education on fertility from a gendered approach. Two important results emerge: (i) significant and negative association between education and fertility is found, and (ii) such a relationship is non-uniform over the distribution of education/fertility. While our results suggest the existence of a negative and significant effect of the female endowments in human capital on the fertility transition, the effects of negative endowment almost disappear at a low level of fertility.
\end{abstract}

Keywords: Gender difference; Cliometrics; Individuals' choice; Education; Fertility; ; Quantile regression; Unified growth theory; Nineteenth century France; Quality-Quantity trade-off.

JEL Codes: C22, C26, C32, C36, C81, C82, 120, J13, N01, N33.

\footnotetext{
* Claude Diebolt: BETA/CNRS (UMR 7522), Université de Strasbourg, 61 Avenue de la Forêt Noire, France (e-mail: cdiebolt@unistra.fr); Tapas Mishra: Southampton Business School, University of Southampton, United-Kingdom (email: t.k.mishra@soton.ac.uk); Faustine Perrin: BETA/CNRS (UMR 7522), Université de Strasbourg, 61 Avenue de la Forêt Noire, France, and Department of Economic History, Center for Economic Demography Lund University, Box 7083, SE-22007, Sweden (e-mail: faustine.perrin@unistra.fr, faustine.perrin@ekh.lu.se).
} 


\section{Introduction}

What explains transition of an economy from stagnation to a sustained growth path? Recent development of growth models being influenced, in particular, by unified growth theory (Galor and Weil, 1999, 2000; Galor, 2005, 2012) provide strong foundation to an empirical apparatus that sees gender inequality as a potential explanation of quality-quantity trade-off between fertility and education. Individuals' choice for more education or more fertility (or no fertility at all), can be driven by gender differences. ${ }^{1}$ Diebolt and Perrin $(2013,2019 a)$ developed a gendered approach to unified growth theory and offered theoretical insights into the dynamics of choice function between male and female for choosing education and fertility. The current paper is an empirical extension of this theory. For the purpose, we exploit a unique historical census data for French counties to infer that the gender distribution holds essential information on quality-quantity tradeoff regarding individuals' choice between education and fertility. The reflections from the past, of course, has implications for the present; despite a century having passed, inequality still holds fort while driving individuals' choice.

The analysis of transversal and longitudinal data from France over the course of its development process uncovers key socio-economic, demographic, geographic, and cultural patterns that have marked a turning point in the French economic history. ${ }^{2}$ France - as other Western countries experienced major demographic changes over the past two centuries, e.g. decline in mortality, increase in population, decline in fertility, and expansion of life expectancy at birth, among others. However, France experienced its fertility transition almost a century prior to other European countries (Chesnais, 1992). Despite an overall increase in the availability of resources, the number of offspring radically declined. In parallel to the fertility transition, profound changes affected the structure of the population. Formal education became accessible to a vast majority of the population. The investigation of educational investments shows strong differences between boys and girls.

\footnotetext{
${ }^{1}$ Hazarika, Jha and Sarangi (2019), in a recent important work, argue that gender inequality is important in perceived wellbeing in pre-history in regions less endowed with ecological resources.

${ }^{2}$ See Perrin (2013) for a detailed description of the long-run and regional evolutions of education during the French development process.
} 
In the early 19th century, women were on average less trained than men. Women opportunities and access to education were limited and bounded. Additional education was often limited to specific knowledge related to housework and skills required for their future role within the household as mother and wife. The 19th century marked deep improvements in individuals' endowments in human capital. While a huge share of the population was illiterate in the early 19th century, only a small fraction of the population remained unable to read and write at the turn of the 20th century. The feminization of education - notably through the implementation of laws and decrees (Pelet 1836, Duruy 1867, Sée 1879 or Bert 1879) encouraging the development of infrastructures - allowed girls to fill up a large part of their delay in schooling. Educational investments gradually diffused across the French departments throughout the 19th century.

The opposite evolution between the number of children and the average education level may give credit to rational choice explanations, as questioned by de la Croix and Perrin (2018), according to which parents derive utility from both offspring quantity and quality (Becker, 1960; Becker and Lewis, 1973). ${ }^{3}$ The child quantity-quality trade-off has been historically hailed as the main motivator of the celebrated transition from Malthusian stagnation to sustained economic growth of recent times. The latter hypothesis has found both considerable theoretical attention - especially in unified growth theoretic tradition (following Galor and Weil, 1999, 2000; Galor, 2005, 2012), and vigorous empirical analyses over the past decades. Despite a renewed interest in recent years (see Cinnirella, 2019 for an exhaustive review of literature on the relationship between parental investments in children's education and fertility) to uncover the existence of a possible causality between quantity and quality of children, important questions remain: Does the quantity-quality trade-off (if there is any) exhibit monotonicity over the distribution of the dependent variable or it is just an empirical artefact of only one point of the distribution? Is there any gender-bias in the quantity-quality trade-off, as suggested by Diebolt and Perrin (2013, 2019a)? For apparent theoretical and policy reasons, heterogeneity in the existence of such a relationship over the entire distribution of education or fertility may have varied implications. An educational policy indeed can influence a shift in institutional path - from a stagnation to growth an such a change is manifested by policy decisions that influence individuals' choice. Recent research has shown that economic policies contribute directly to a shift in institutional paths (Hartwell, 2019).

\footnotetext{
${ }^{3}$ See Doepke (2015) for a thorough presentation of Gary Becker's theory and its developments.
} 
The main purpose of the current article is to contribute to the burgeoning literature about the relationship between education and fertility ${ }^{4}$ by employing the recent development in quantile regression literature to account for full distributional effects of changes in educational status (of boys and girls/men and women) on fertility transition. We consider both the short-run and the long-run nexus between education and fertility. To do so, we use county-level data collected from diverse publications of the Service de la Statistique Générale de la France. Our dataset covers information about aggregated individual-level behavior for 86 French counties (départements). ${ }^{5}$ First, we investigate the two directions of causality between child quantity and child quality in the mid-19 ${ }^{\text {th }}$ century France using simultaneous quantile regression framework - which is known to allow significant heterogeneity in the slope estimates over the distribution of the dependent variable. Possible endogeneity bias is corrected by employing an instrumental variable quantile regression approach for both education and fertility equations. Our results show evidence of a significant interaction between quantity and quality of children in $19^{\text {th }}$ century France. Second, based on the same method, we study the long-run impact of the accumulation of human capital on the demographic transition during the 19th century. Our incentive is to check whether parental investment in education has an effect on the ability of their children to succeed in education (process driving to the accumulation of human capital). We find that the fertility transition in France was significantly more pronounced in counties with higher female endowment in human capital.

The rest of the paper is planned as follows. Section 2 presents data and describes various distributional characteristics. Section 3 presents our methodological approach and empirical construct. Section 4 discusses various results including robustness. Finally, Section 5 concludes with discussions of main findings.

\footnotetext{
${ }^{4}$ See for instance, Becker et al. (2010, 2012), Fernihough (2017) for studies about Prussia, Ireland, respectively; Clark and Cummins (2016), Klemp and Weisdorf (2019) for studies about England; Murphy (2015), Bignon and García-Peñalosa (2016), Diebolt et al. (2017), de la Croix and Perrin (2018) for studies about France.

${ }^{5} 1851$ France consists of current metropolitan French départements except Alpes-Maritimes, Savoie and Haute-Savoie.
} 


\section{Data}

\subsection{Sources and descriptive statistics}

The major part of the dataset is constructed from General Censuses, Statistics of Primary Education, Population Movement and Industrial Statistics conducted in 1851 (1850 for Education, 1861 for Industrial Statistics). The rest of the data stems from diverse sources. A part of fertility data is available from the Princeton European Fertility Project (Coale and Watkins, 1986). Data on life expectancy at birth come from Bonneuil (1997). A combined use of the various Censuses allows us to construct a dataset with detailed information on fertility, mortality, literacy rates, and enrollment rates in primary schools for both boys and girls, employment in industry and agriculture by gender, level of urbanization and stage of industrialization. In addition, we use data from French Censuses for the years $1821,1835,1861,1881$ and 1911 to get more demographic and socioeconomic information necessary to carry out our analysis.

In the short-run analysis, we use the crude birth rate as a measure of fertility behavior, defined as the number of birth per thousand people. The reason for using CBR is that it is well-suited to construction from vital registration and census data. Moreover, it is easy to calculate when using historical data. For robustness analysis, we have used General Fertility Rate which is measured as the number of births per women in age of childbearing (15-49). There are of course alternative measures of fertility suggested in the literature, for instance, index of marital fertility (used in Murphy, 2015). However, this measure inherits some important limitations; Sanches-Barricarte (2001) argues that this indicates is not a good indicator when there is important delay in female mean age at marriage. Indeed, this was the case for several counties in France in the middle of the $19^{\text {th }}$ century (see Perrin, 2013, p. 52). This led us to choose a simple measure, CBR, which is frequently used and suffer less from these misspecification biases.

To measure education, we use enrollment rates in public primary school in 1850 , constructed as the number of girls (boys) attending school divided by the total number of girls (boys) aged 6-14. The main specifications applied in our analysis are expected to capture: (i) the variations in fertility with educational level and in education with fertility level; and (ii) the supply and demand factors represented by a set of control variables. The supply and demand factors aim at capturing both 
economic and cultural factors likely to have impacted educational and fertility behaviors. The demand for children, for instance, depends on the opportunity cost of having children. Based on the prediction of theoretical models, we expect income to affect fertility. As a proxy for the income level, we use the urbanization level, the population density, as well as the employment opportunities, measured by the share of women (men) employed in manufacturing and in agriculture. As a control for the supply of children, we use the life expectancy at birth. The life expectancy at birth allows controlling for the decline in infant mortality and may be a proxy for the lengthening of both the individual longevity and the reproductive period. We also control for religion in order to account for cultural differences that may have affected individuals' behaviors in regards with fertility (birth control) and education (Lutheran ideas). As a measure a religious practices, we use the share of Protestants within the population.

For the long-run analysis, we use literacy rates to capture the amount of human capital accumulated. One limitation (already raised by Becker et al., 2010, 2012) of using enrollment rate in education relates to the fact that attendance at the census date might not be the same as yearround attendance what prevent from capturing the amount of human capital accumulated. We use similar control variables to the one used in the short-run analysis. Hence, we control for the level of urbanization, employment opportunities, and religious practices. As additional controls, we use the crude birth rate in 1851 in order to address potential issues raised by intergenerational correlation of fertility. In order to account for differential fertility development that might have occurred before the fertility transition, investigated over the period 1881-1911, we control for the initial level of fertility in 1881, measured by the crude birth rate.

Table 1 reports descriptive statistics of the variable used in our analysis. In general, the statistics evince heterogeneity in our variables across counties and over time. In 1850, 54.5\% of boys aged 614 were enrolled in public primary school, while the enrollment rate in public primary school for girls was $36 \%$. Some counties dedicated important effort on educational investments for boys but also for girls, i.e. counties located in the northeastern diagonal part of France. Enrollment rates spread from $19 \%$ to $106 \%$ for boys and from $0.3 \%$ to $99 \%$ for girls in $1850 .{ }^{6}$ The period $1850-1867$ recorded fast changes. The number of counties with girls' enrollment rates higher than $50 \%$

\footnotetext{
${ }^{6}$ Enrollment rates above $100 \%$ are due to the possibility that children below 6 years old and above 14 years old were enrolled in public primary schools.
} 
expanded significantly. This fast increase was followed by a consolidation period, between 1867 and 1876 during which national enrollment rates increased from $66 \%$ to $72.3 \%$. The increase in schooling between 1867 and later periods occurred mainly through the catch up of counties which were originally lagging behind. In $1881,70.84 \%$ of boys and $57.16 \%$ of girls (aged $5-15$ ) were enrolled in public primary schools. ${ }^{7}$ These variations can be explained by several factors: the diffusion of the official French language, the difference in attitudes toward education between Catholics and Protestants (Becker and Woessmann, 2009), the wave of spreading ideas coming from Prussia and the insufficiency of educational resources deployed in rural areas in terms of teachers and financial spending.

Figure $1 \mathrm{a}$ and $1 \mathrm{~b}$ display the geographical distributions of boys and girls enrollment rates in 1850 . The maps highlight a development gap between Northeastern-France and Southwestern-France separated by the famous line Saint-Malo/Genève. Similar to Prussia (see Becker et al., 2010), the most industrialized area (the Northeast part in France) shows higher enrollment rates. These variations may also find explanations in the different attitudes toward education between Catholics and Protestants as advanced earlier and by the insufficiency of educational resources in terms of teachers and financial spending deployed in rural areas.

The rural and more agricultural remainder of France displays higher fertility rates in 1851, as evidenced by Figure 1c. Similar to education, data on fertility show an important heterogeneity across counties. These differences support the evidence that some counties have adapted their fertility behavior and therefore experienced a demographic transition before others.

Table 1 - Summary statistics

\begin{tabular}{lccrr}
\hline & & & & \\
\hline & Mean & Std. Dev. & Min & Max \\
\hline Education & & & & \\
School enrollment rate (1850) & 0.454 & 0.229 & 0.133 & 1.029 \\
Boys enrollment rate (1850) & 0.544 & 0.211 & 0.188 & 1.059 \\
Girls enrollment rate (1850) & 0.356 & 0.259 & 0.003 & 0.997 \\
Boys enrollment (1850-67) & 0.600 & 0.342 & -0.076 & 1.624 \\
Girls enrollment (1850-67) & 1.067 & 1.962 & 0.017 & 17.485 \\
Male literacy (1856-70) & 0.113 & 0.092 & -0.093 & 0.358
\end{tabular}

\footnotetext{
${ }^{7}$ This does not appear in the summary statistics but is available in the data.
} 
Female literacy (1856-70)

Boys schools (1850)

Girls schools (1850)

Distance to Mainz (in km)

Fertility

Crude birth rate (1851)

Index of marital fertility rate (1851)

Crude birth rate (1881)

Crude birth rate (1881-1911)

Marital fertility rate (1851)

Marital fertility rate (1881-1911)

\section{Economic}

Share in industry (1851)

Share in agriculture (1851)

Male in industry (1851)

Male in agriculture (1851)

Female in industry (1851)

Female in agriculture (1851)

Urbanization (1851)

Population density $\left(\mathrm{km}^{2}\right)$ (1851)

Male wages in agriculture (1852)

Female wages in agriculture (1852)

\section{Demographic}

Male life expectancy at age 0 (1856)

Female life expectancy at age 0 (1856)

Share married women (1851)

Male workers (1861)

Female workers (1861)

Adult sex ratio (1851)

Infant mortality (1851)

Child mortality (1851)

$\begin{array}{rrrr}0.271 & 0.213 & -0.085 & 0.956 \\ 1.217 & 0.588 & 0.143 & 2.616 \\ 0.152 & 0.170 & 0.005 & 0.907 \\ 699 & 248 & 181 & 1222\end{array}$

26.95

3.597

18.717

34.275

0.497

0.109

0.298

0.747

24.22

3.798

17.28

34.57

$-0.245$

0.092

$-0.405$

$-0.002$

3.218

0.579

2.07

4.77

$-0.290$

0.091

$-0.476$

0

0.029

0.047

0.370

0.426

0.106

0.081

0.171

0.070

0.179

0.074

3.166

0.287

0.186

0
0.031

0.655

0.636

1.135

0.046

0.552

0.615

0.029

1.011

1.414

0.892

38.080

4.424

26.454

48.960

40.556

4.834

27.506

49.846

$0.534 \quad 0.057$

0.430

0.641

11918

19106

735

141905

5271

8167

215

54062

0.993

0.063

0.810

1.194

0.301

0.078

0.162

0.483

0.040

0.012

0.019

0.068

\section{Socio-economic}

Share Protestants (1861)

2.258

5.332

0.003

31.298

Note: Detailed description of variables is provided in appendix 


\section{Figure 1: Geographical Distribution of Education and Fertility}

(1a) Boys Enrollment Rate, 1850

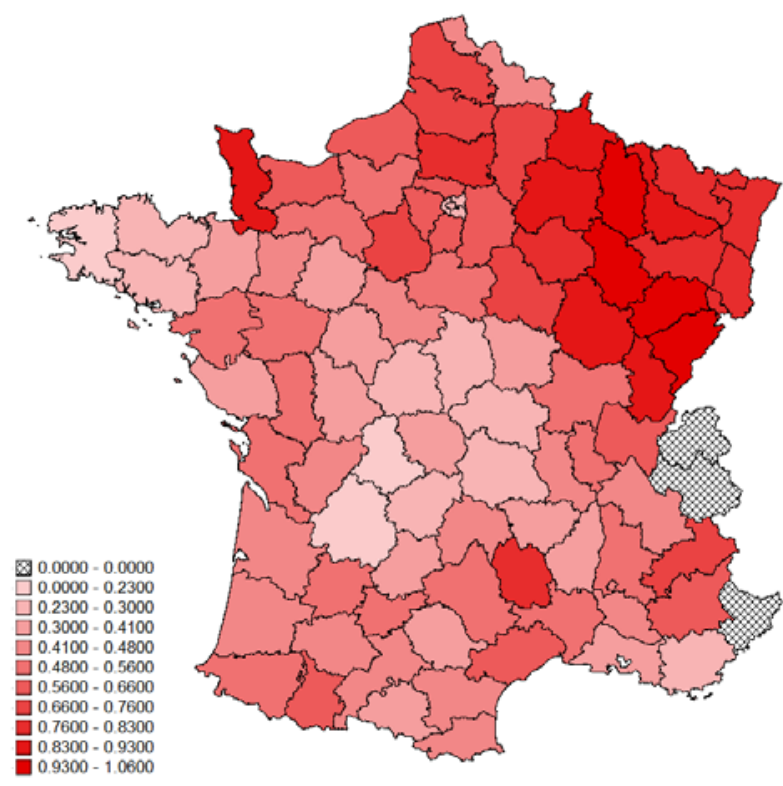

(1b) Girls Enrollment Rate, 1850

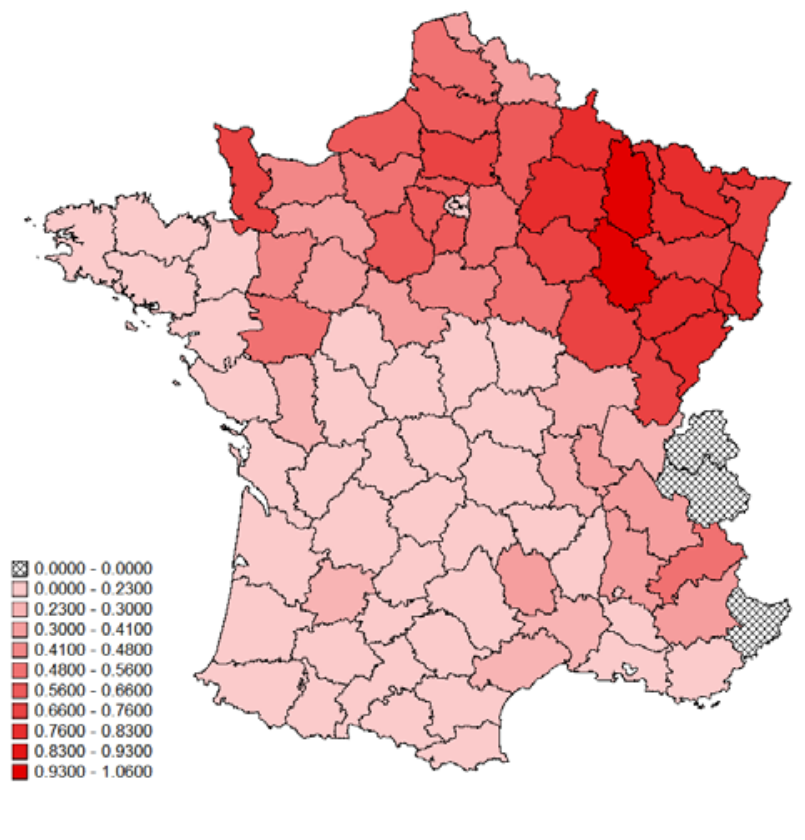

(1c) Crude Birth Rate, 1851

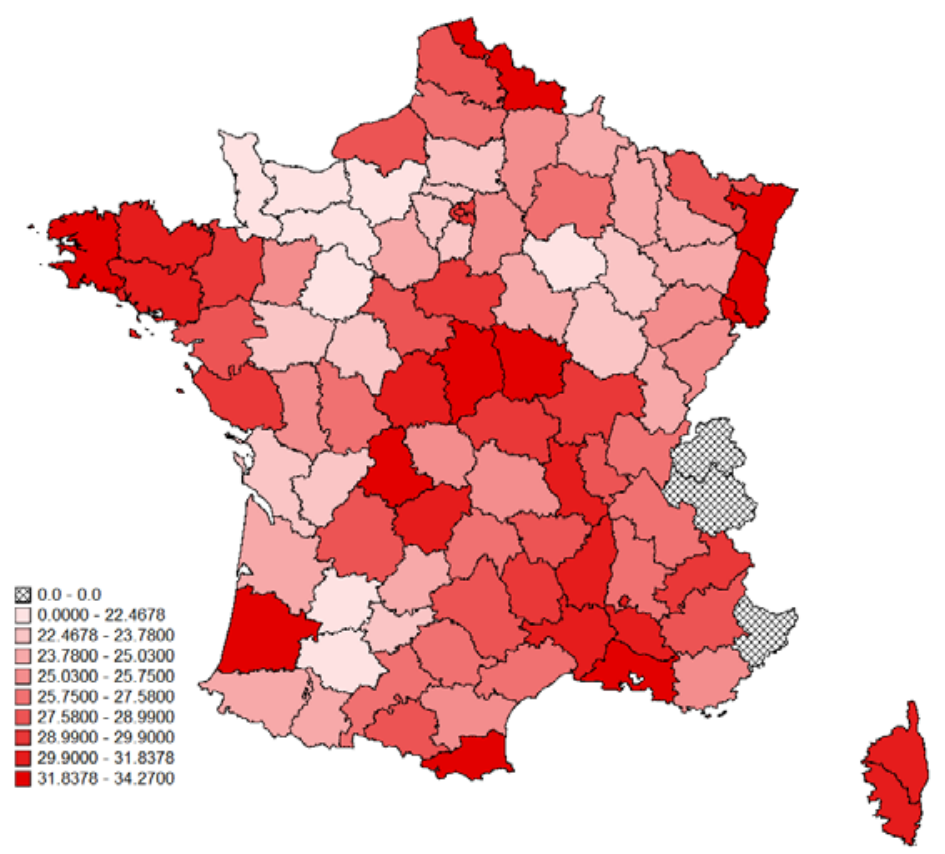

Sources: Using data from Statistique Générale de la France - Enseignement Primaire 1850; Census 1851 
A crude birth rate close to 40 is considered as a natural level of fertility, i.e. the level of fertility that would prevail in a population making no conscious effort to limit, regulate or control fertility (Henry, 1961). According to Chesnais (1992), a crude birth rate below 30 per one thousand individuals marks the entry into a regime of controlled fertility; a crude birth rate below 20 children per one thousand individuals suggests that a large share of the population practice birth control. In 1851 , the average crude birth rate was $27 \%$, ranging from $18.72 \%$ o to $34.27 \%$ o. In 1851 , 19 counties over 86 exhibited a crude birth rate above 30 children per thousand individuals. Thirty years later, in 1881 , the average fertility rate decreased to $24 \%$, with minimum and maximum crude birth rates equal to $17.28 \%$ and $34.57 \%$, respectively. Seven counties only (all located in the periphery of the country) exhibited crude birth rates above 30 children per thousand individuals.

Two opposite profiles emerge from the analysis of socio-economic and demographic characteristics of French counties in the mid-19th century. On the one hand, we find agrarian counties characterized by a poorly educated population and higher fertility rates. On the other hand, we find industrialized, but still rural areas putting significant effort on education for both genders, women tend to be more integrated in the labor market, and fertility rates seems to be lower. The investigation of regional characteristics emphasizes the importance of considering the educationfertility relationship from a gender perspective.

\subsection{Distributional Characteristics}

We presented above the distributional characteristics of fertility and education to motivate the development of required estimation tool for testing hypotheses on quality-quality trade-off. This subsection presents the density plots of these variables to detect possible multimodality or cluster dynamics in the data.

Our next focus is on detecting if the (statistical) distribution of these variables presents any evidence of multimodality. This is important for several reasons; one of them being that such evidence would guide us in choosing the correct estimation method - for instance, whether to focus on the 'mean-based' conventional OLS method or to adopt 'quantile-based' full distributional method. Another leading reason is that any evidence against unimodality of distribution of these variables would indicate possible presence of multiple equilibria/clusters, leading to variable 
inferences at various points of the distribution the dependent variable. Alternately speaking, it might be possible for instance, that the response of fertility to low educational attainment level is significantly different (both quantitatively and direction of causality-wise) from the one at high educational attainment levels. From theoretical perspective, this makes sense as one would expect the existence of quality-quantity theory primarily at higher educational achievement levels leading to gender equality in education and female empowerment. The choice of fewer children then becomes essentially a reflection of investigation of the relationship at higher quantile of the distribution of the variable. The non-uniqueness of fertility-education trade-off relationship at various quantile of the distribution (instead of just focusing on the mean of the distribution, i.e., OLS) is more informative and would enable us to test the validity and consistency of the theory at various points of the distribution.

Following this idea, we have presented Adaptive Kernel density plots of crude birth rate (Figure 2a.1) and enrollment (Figure 2a.2). It needs mentioning at this point that adaptive Kernel density extends the possibilities offered by Kernel density estimation in two ways: first, it allows the use of varying, rather fixed bandwidth. Second, it provides estimation of pointwise variability bands. Following this density estimation, these two figures present evidence of significant bimodality which is further confirmed by Hartigan and Hartigan's (1985) Dip test. In case of fertility, the crude birth rate mean is 26.976 with a standard deviation of 3.610. However, Figure 2a.1 presents two significant modes (one around 30 years and another at 25 years). These modes, as confirmed by Diptest are significant at 5\% level. Likewise, education (enrollment rates) for both men and women also depict significant bimodality (weaker for men - Diptest accepted at $10 \%$ level) whereas it is stronger for women (accepted at $5 \%$ level).

Figures $2 \mathrm{~b} .1$ and $2 \mathrm{~b} .2$ present the bivariate Kernel density plots for CBR and enrollment rate (boys and girls). The contours reflect the fact that low educational attainment for girls evinces higher fertility rate, which is far greater than that of the male with similar enrollment scale. Moreover, we have also performed a skewness test of $\mathrm{CBR}$ as well as the enrollment rate for boys and girls. Figure 2c (2c.1 for male enrollment, 2c.2 for female enrollment, and 2c.3 for CBR) present the skewness plots. A rising graph implies that there is significant bias to the right of the distribution and the distribution is not normal. Indeed, all three graphs depict the expected pattern: they are rightskewed distributions and therefore the mean and the mode of these distributions are markedly 
different. These results and the reasons cited above motivate us to go beyond conventional OLS based estimation method, as the estimated coefficients may be either under- or over-estimated and may not present the complete picture of the response of education to changes in fertility (and the converse). Alternative estimation method, such as quantile regression technique, has been found to be very useful in this regard. We present them in the next section.

Figure 2a: Distributional Characteristics of Fertility and Education

(2a.1) Distribution for crude birth rate (CBR)

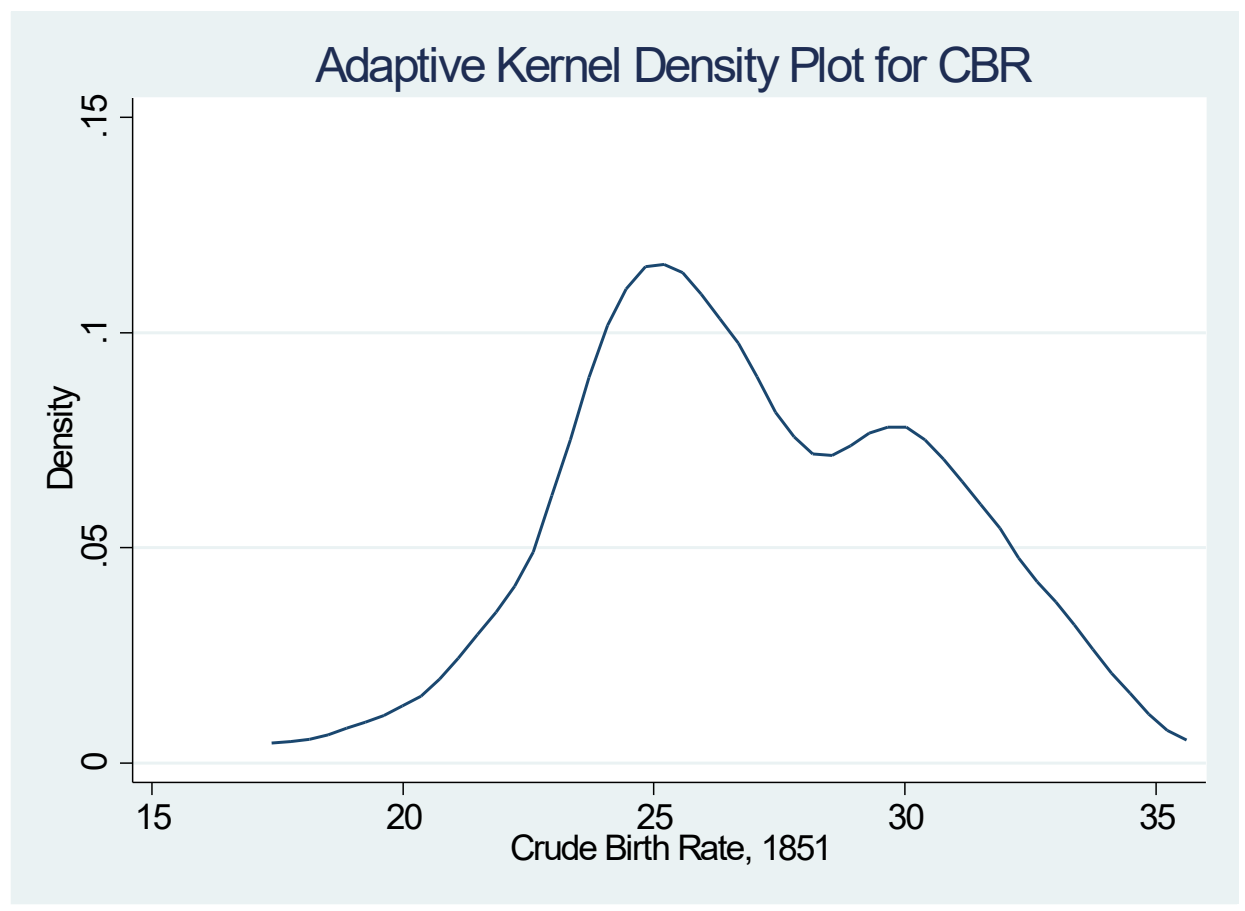

(2a.2) Distribution for enrollment rate 


\section{Adaptive Kernel Density Plots: Male [Left], Female [Right]}
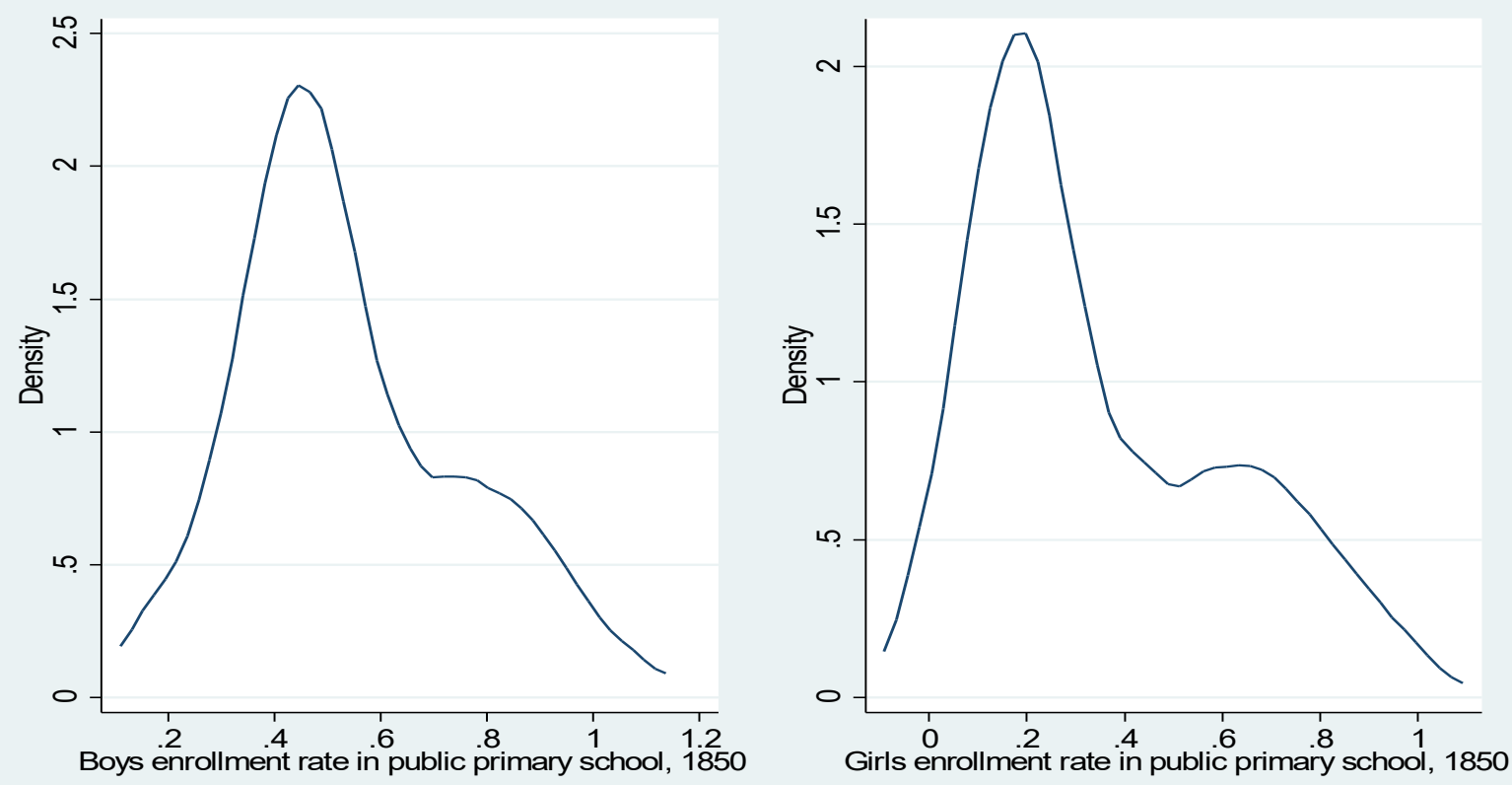

Figure 2b: Bivariate Density Plots for Fertility and Education: Boys and Girls

Figure 2b.1 Boys

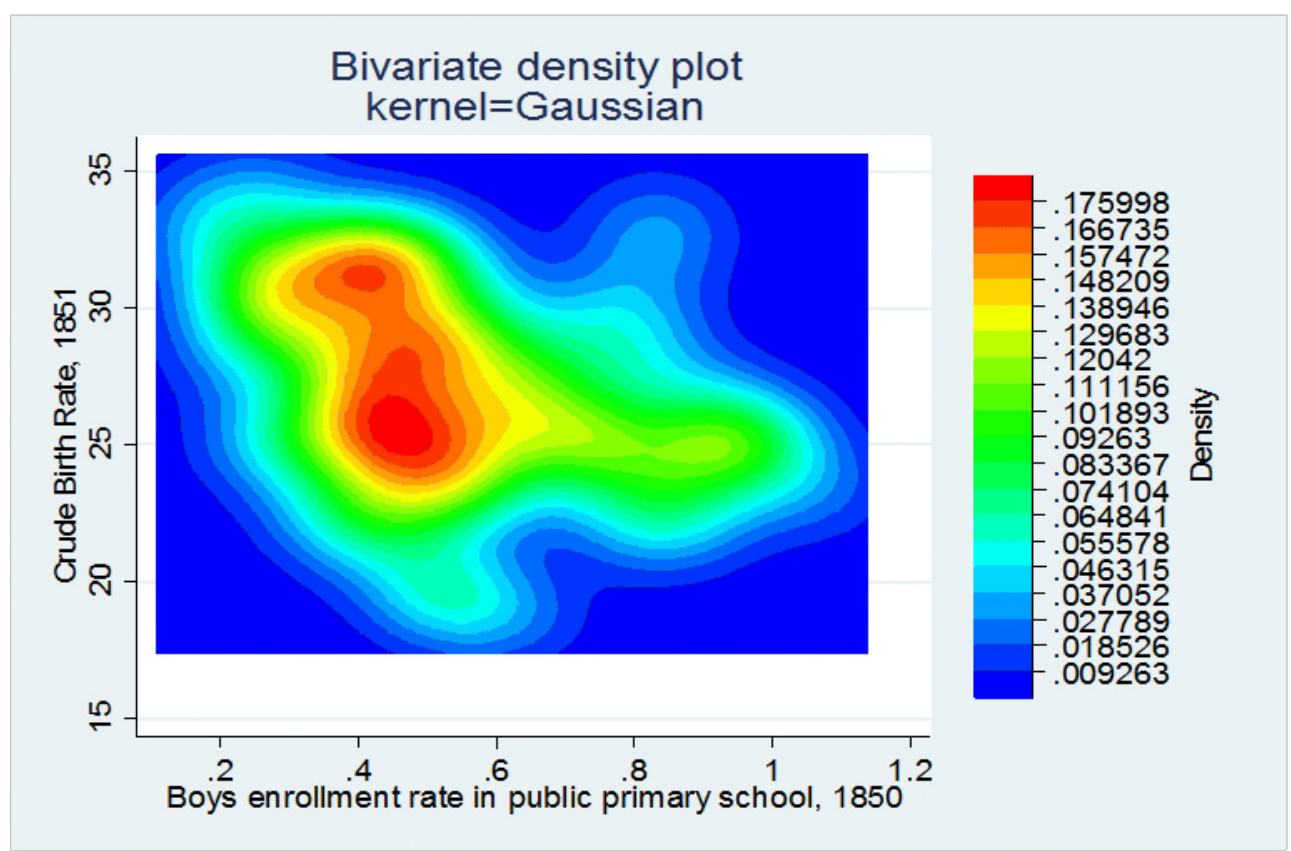


Figure 2b.2 Girls

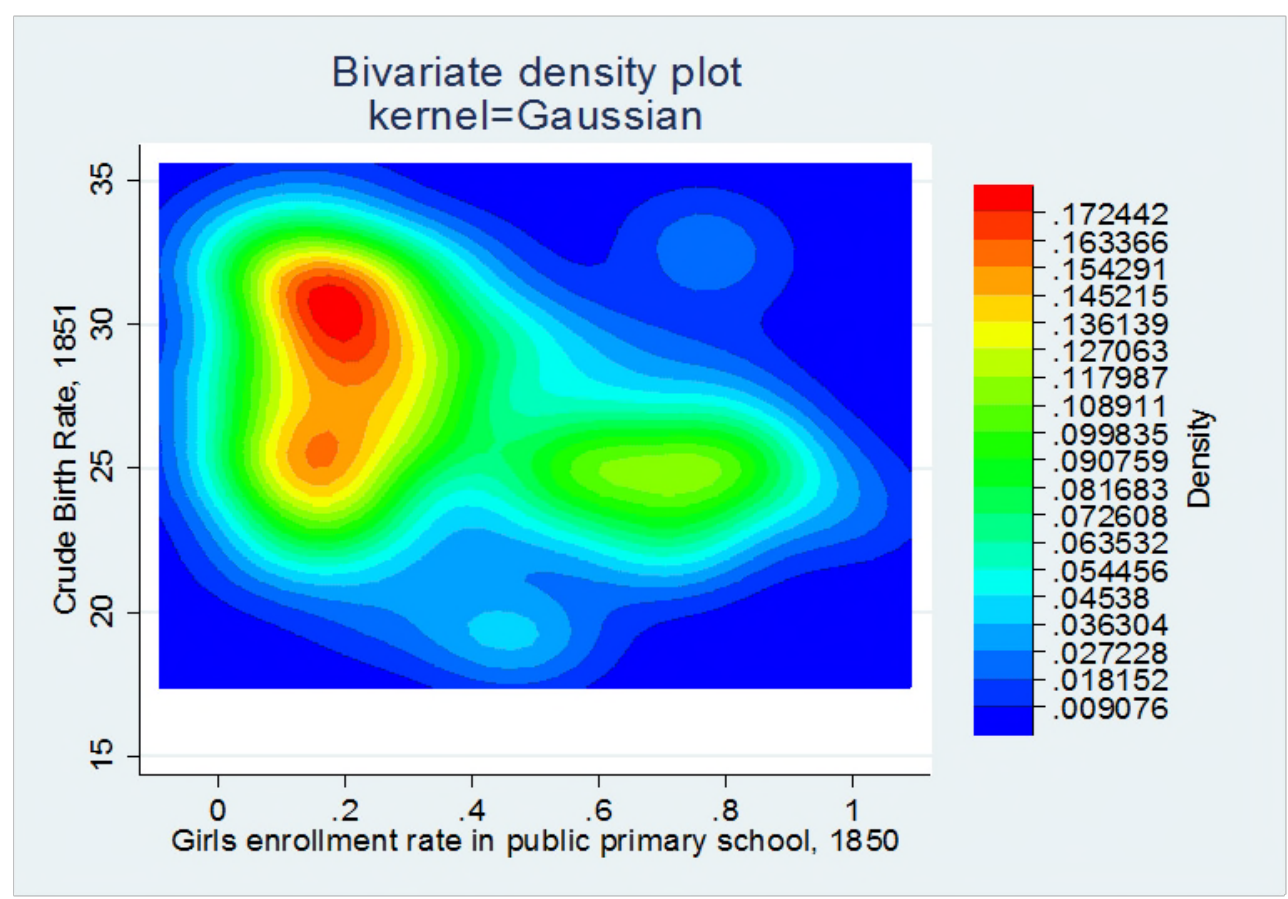

Figure 2c: Skewness Test

Figure 2c.1: Boys Enrollment

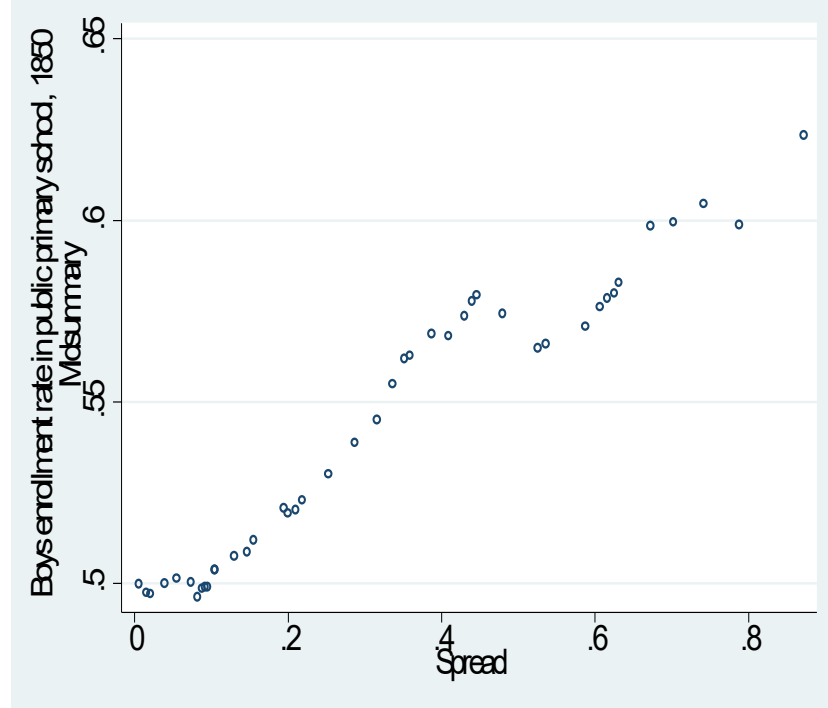

Figure 2c.2: Girls Enrollment

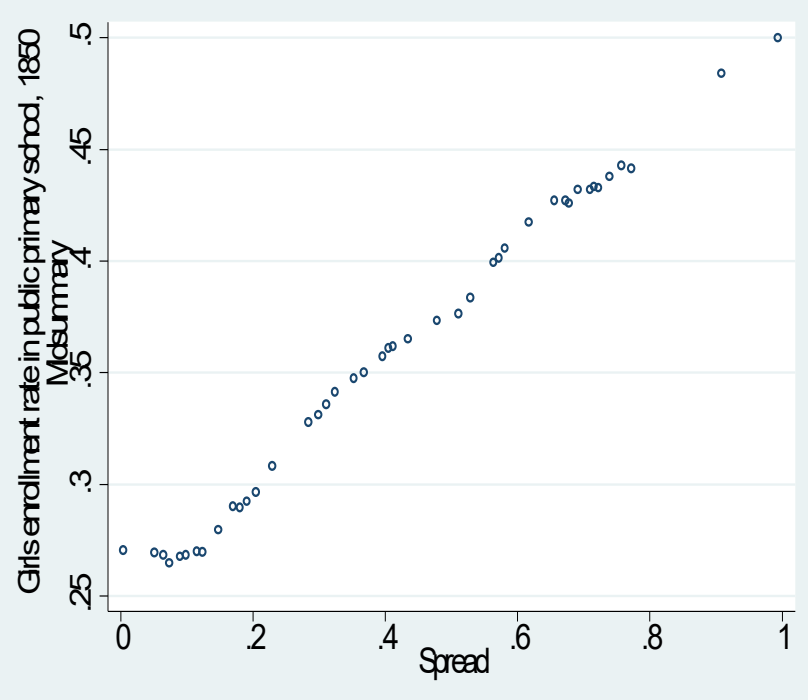


Figure 2c.3: Crude Birth Rate

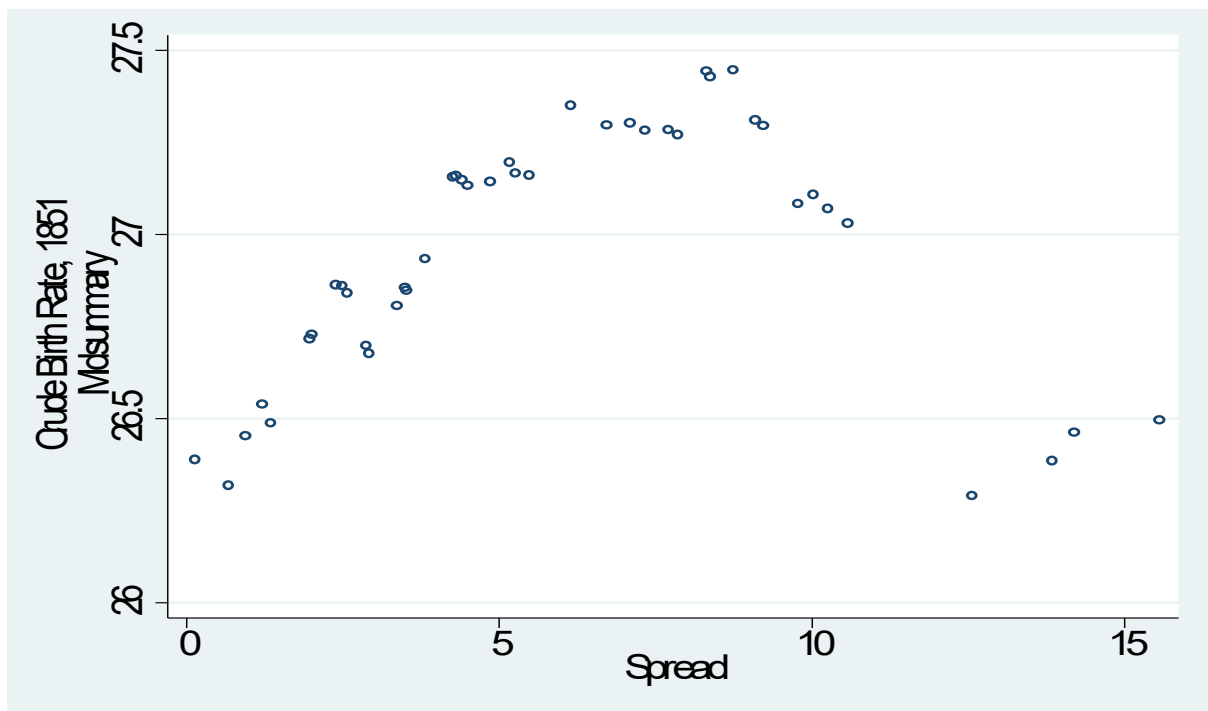

\section{Methodological setting}

In this section we develop and present the methodological construct that would adequately account for sensitivity of the education-fertility relationship to distributional heterogeneity. Towards this end, we first describe the empirical framework and use the same to develop necessary methodological tool.

\subsection{Empirical construct}

Short-run. - We investigate the short-run relationship between investment in human capital and fertility. Following the work done by Becker et al. (2010), we differentiate between the two directions of causality: from education to fertility and from fertility to education. We estimate the following empirical models separately (Wooldridge, 2002):

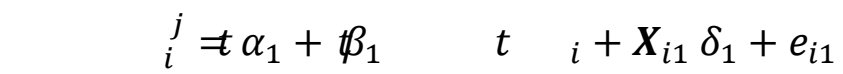

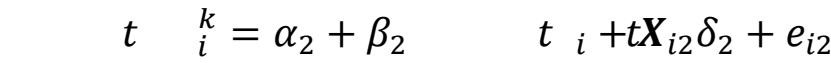




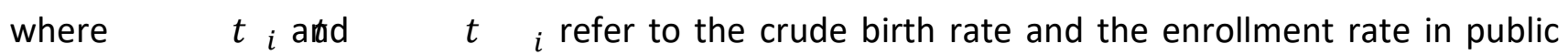
primary schools for each county $i$. The coefficients $\beta_{1}$ and $\beta_{2}$ are our parameters of interest. $\boldsymbol{X}_{1}$ and $\boldsymbol{X}_{2}$ are the vectors of control variables.

Long-run. - We use equation (3) to test the hypothesis that increasing investment in education might have played a significant role in the fertility transition:

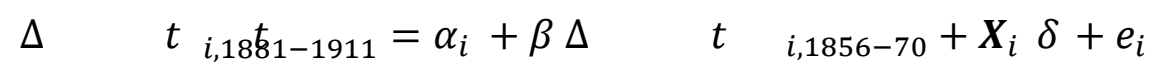

where the percentage change in the crude birth rate between 1881 and 1911 is the dependent variable and the percentage change in literacy rates between 1856 and 1870 is our variable of interest. $\boldsymbol{X}$ is the vector of control variables (see Appendix for a detailed description of the variables). The time lag of twenty five years between the dependent and the explanatory variable prevents from having a direct simultaneity between the variables.

We estimate equations (1) - (3) by using quantile regression approach. The motivations for preferring quantile method to ordinary least squares (OLS) have been presented in Section 2. Based on quantile approach (with and without instrumentation), our main incentive is to investigate: (a) to what extent the level of male education at time $t$ is influenced by the level of parental fertility at time $t$; and (b) to what extent the level of girls education at time $t$ is determined by the level of parental fertility at time $t$.

Indeed, investigating the relationships from a gendered perspective allows us to compare the respective effects of boys and girls education on fertility and the effect of fertility respectively on boys' education and on girls' education. We keep in mind that we suspect a bi-causal relationship between fertility and education. Unobserved characteristics affecting schooling choices are potentially correlated with unobservable factors influencing the decision to have children (and inversely). Estimating a causal relationship may consequently be biased by some potential endogeneity of each of our variables of interest. This is accounted for by employing an instrumental variable quantile regression approach. Nonetheless, our main motivation in this article is not to measure the exact causation but to have intuitive results on the fertility-education nexus. 
To control for the main determinants of fertility and education The covariates used in the regression analysis are: (i) proxies for the level of industrialization specified as the level of urbanization $^{8}$ and the population density; (ii) employment opportunities measured by the share of people making their living of agriculture and the share of people employed in manufacturing; (iii) the share of Protestants; and (iv) the life expectancy at age 0.

\subsection{Estimation and identification strategy}

Limitations of OLS with respect to representativeness of heterogeneity of slope estimates especially in the presence of cross-sectional heteroscedasticity across the distribution - are well known. Moreover, as reflected in Section 2, the distributions of both education and fertility are found to possess non-unique mode necessitating the use of an alternative estimation method rather than the conventional OLS. One can, for instance employ non-parametric method and compare the distribution of the dependent variable and the regressor. However, these methods inherit the natural limitation of focusing on the mean of the distribution and its changes in the shape of the distribution. What is required, however, is the effect of the regressor on the entire distribution of the dependent variable. Quantile regression approach has been proved very useful in this regard (Koenker and Bassett, 1978, for instance). In quantile regression, by specifying different covariate effects at different quantile levels we allow covariates to affect not only the center of the distribution (that is mean-based OLS estimation), but also its spread and the magnitude of extreme events. Indeed, by using quantile model we allow for unobserved heterogeneity and heterogeneous covariate effects. In addition, quantile regression allows for some conditional heteroskedasticity in the model (Koenker and Portnoy, 1996), and is a method that is more robust to outliers

Recalling the quantity-quality trade-off problem in equation (1) and denoting, fertility as $(F)$, education as $(E)$, and other variables as $(X)$, we can re-write the vectorial notation as follows:

$$
\begin{aligned}
& F=\beta \text { 田 } \gamma X^{\prime}+\varepsilon \\
& X=f(z, u) \\
& \varepsilon=\mu+u
\end{aligned}
$$

\footnotetext{
${ }^{8}$ The level of urbanization is defined as the share of people living in towns populated by more than 2000 inhabitants.
} 
We assume that education $(E)$ not only affects fertility $(F)$ but also life expectancy, urbanization, and many other variables (denoted in our equation as $X$ ). $z$ is a vector of instruments which drive education but are uncorrelated with $u$ and $\varepsilon$. Moreover, $\mu$ are country specific factors affecting the evolution of $F$ and $E$. As evident, we are interested in estimating $\beta$, the causal effect of education on fertility, at different quantiles of the conditional distribution of fertility. The following possibilities arise:

(i) Mean based regression

In a typical least squares approach, one may focus on estimating:

$$
E\left(F_{i} \mid E_{i}, X_{i}\right)=\beta E_{i}+\gamma X_{i}
$$

In equation (5), $\beta$ captures the 'average' response of fertility due to a small change in educational attainment and other variables. What is missing in this estimate is the possibility of heterogeneous response of fertility to changes in the explanatory variables. It is now well-known that average response of the dependent variable is less informative of the actual dynamics that occurs between the regressors and the full range of distribution of the dependent variable. Indeed, this is the case in the present context. As demonstrated before, the unconditional distribution of fertility is strongly bimodal. Thus, it seems that the analysis that focuses on the (conditional) mean of the distribution might miss important distributional effects of education and other variables on fertility. To capture this effect, quantile regression will offer a wholesome view of the effect of education on the entire distribution of fertility (or vice versa as in equation 3). Given the cross-sectional nature of our data, we adopt the following cross-sectional quantile regression framework.

(ii) Median regression: (Quantile) regression

$$
Q_{F_{i}}\left(\tau \mid E_{i}, X_{i}\right)=\beta(\tau)+\gamma(\tau) X_{i}
$$

The parameter $\beta(\tau)$ captures the effect of education at the $\tau$-th quantile of the conditional distribution of fertility. This model can be estimated by solving the following minimization problem: 


$$
\min _{\beta, \gamma} \sum_{i=1}^{N} \rho_{\tau}\left(F_{i}-E_{i}-\gamma X_{i}\right)
$$

where $\rho_{\tau}(u)$ is the standard quantile regression check function (see, e.g., Koenker and Bassett, 1978; Koenker, 2005). The partial effects for education on fertilty can be obtained by $\frac{\partial Q_{t}\left(F_{i} \mid E_{i}\right)}{\partial E_{i}}$.

\section{Identification strategy - Endogeneity issue}

Two types of endogeneity problems can plague regressions of education on fertility. One type is the simultaneity bias introduced by the reverse causality of education and fertility (equation 3). A second type of endogeneity problem arises from omitted variable bias. While including policy variables helps reduce the problem of the endogeneity of education, it is still quite plausible that a third variable jointly causes both fertility and education - perhaps religious, cultural or geographic factors. In order to mitigate the problems of endogeneity, we innovate upon the previous literature by employing an instrumental variables approach in our cross-sectional quantile regression (see for instance, Chernozhukov and Hansen (2005) and Harding and Lamarche (2009) for detailed estimation procedures). The question may arise on the choice of instruments. Because we have two different channels (fertility to education and the reverse) for quantifying quantity-quality trade-off, several possible instruments can be considered. In case of fertility-education channel (equation 1), there are a number of possibilities for instrumenting education. For instance, one can use enrollment in 1851, distance to Mainz, share of male (female) spouse signing the contract 1816-20, landownership inequality in 1835, agricultural inequality, public primary schools for 100 boys and girls. Murphy (2015), interestingly noted that 'no valid instruments were available' for France to deal with the problem of potential endogeneity of education. However, the mentioned potential instruments in our article (as will be explained in the following section), work well as alternative measures for instruments of education in France.

Similarly, when we consider the reverse channel, i.e., education-fertility relationship, the possible instruments for fertility are crude birth rate of the previous generation (in 1821), adult sex ratio 1545 , share of dependent children in 1851 , children and non-married sex ratio in 1821,1831 , and 1836. As we know, all instruments may not identify the dependent variable and may suffer from weak-identification problem. Moreover, many of them may not be strictly exogenous. The possibility of weak correlation of the instruments with other regressors in the two different 
channels we are interested in estimating can make estimated coefficients unreliable. Therefore, we have performed a Principal Component Analysis of the instruments as well as have performed overidentification test for the purpose. Accordingly, we have chosen the adult sex ratio and the share of dependent children as instruments for fertility, whereas the distance to Mainz and the share of male (female) spouse signing their marriage contract in 1816-20 have been chosen as instruments for education.

\section{Results}

\subsection{Short-run Effects: From Education to Fertility}

Two types of results are presented, viz., quantile regression estimates without accounting for endogeneity bias, and quantile regression estimates accounting for possible endogeneity. Estimations have been performed for both men and women at $10^{\text {th }}, 25^{\text {th }}, 50^{\text {th }}, 75^{\text {th }}$, and $90^{\text {th }}$ quantiles. To minimize space, we have reported in all Tables lower quantile $\left(\tau=25^{\text {th }}\right)$, median quantile ( $\tau=50^{\text {th }}$ - generally regarded as an approximate to OLS estimates), and an upper quantile $\left(\tau=75^{\text {th }}\right)$.

We begin with the case where the dependent variable is fertility (crude birth rate). In all tables, the results are presented in three columns (quantile estimation for each case). Beginning with the restrictive model where only fertility and education variables are considered (model 1), we continue to add more explanatory variables with education: the role of agriculture, industry, urbanization, and population density (model 2), the role of share of Protestants (model 3), and the potential role of life expectancy at birth (model 4).

\section{Average effects}

Overall, looking at all columns, across quantiles, and for both men and women, we find evidence of a quality-quantity trade-off in the short-run, although the magnitudes are observed to vary across the distribution of the dependent variable in question. The $50^{\text {th }}$ quantile - which approximates OLS estimates - shows that the coefficient for education is significant at the $0.1 \%$ and negative for both genders. As per the estimates of median quantile, we observe in Table 2 that in more densely 
populated environments, fertility rates are significantly lower (at $0.1 \%$ ), whereas in more urbanized counties, fertility rates are higher (at 5\%). In line with the latter result, counties with a larger share of male employed in manufacturing exhibit significantly higher fertility rates (at $5 \%$ ). This result may be due to a positive income effect. The male wages are likely to be higher in counties where the industry is more developed what is expected to increase the demand for children. Contrary to what has been found by Becker et al. (2010) for Prussia, fertility is significantly higher (at 1\%) in counties where the share of Protestants is larger (see Table 2 and Table 3). Life expectancy at age 0, however, is negatively associated with fertility. The life expectancy at age 0 is expected to capture the variations in infant mortality. According to the adaptation hypothesis, the decline in infant mortality might have induced individuals to act such as maintaining a sustainable number of offspring by reducing their fertility. Whatever the specification of equation (1), the coefficient of education remains strongly significant and negative for both boys and girls. These results seem to confirm the existence of a negative effect of child quantity on the child quality.

Are the results found at median quantile $\left(50^{\text {th }}\right.$ quantile $)$ significantly different than at low $\left(25^{\text {th }}\right)$ and high $\left(75^{\text {th }}\right)$ quantiles? Do we observe a consistency in the estimated coefficients? The direction and magnitude of effects can be gauged by examining the sensitivity of results at various quantiles of the dependent variable. For the restricted model (column 1 to 3 ), as well as for broader models (models (2) to (4) - column 4 through column 12), the effect of education has been found to be both negative and significant at $1 \%$ level (see Table 2 ). In comparison to the median quantile, both lower and upper quantile estimates of the effect of education on fertility have been found to be small and negative with magnitude of effects at higher quantile observed to be smaller than the one obtained at lower quantile (column 1-column 3). Similar patterns are observed in Table 3 (for women). A monotonic decline in the magnitude of coefficients (although negative) is noted in model (4) (columns 10 to 12) for both Tables 2 and 3 where the most general model is estimated. The heterogeneity in the estimated coefficient of education on fertility (as observed in Tables 2 and 3), clearly demonstrates that OLS based estimates may under-represent the significant variability in the estimates, that is, the response of negative effect of education on fertility being smallest at higher quantile and largest at smaller quantile (column 10 and 12 respectively, in the most general model). Moreover, the $\mathrm{R}^{2}$ value is found to be greatest for the most general model (with a value of 0.402 at $50^{\text {th }}$ quantile) in comparison to 0.123 (for the restricted model, column 1). Of course, within quantile heterogeneity in $\mathrm{R}^{2}$ is also observed, implying that the same explanatory variable 
can have variable predictive power for counties at smaller quantile of fertility distribution than at median and higher quantiles.

\section{IV estimates}

While quantile estimates in Tables 2 and 3 are reflective of the general trend in the empirical literature in quantity-quality trade-off, these may not be taken seriously if there is a possibility of endogeneity bias in the relationship between fertility and education, and vice versa. In the preceding section, we have provided the mechanism and logic of the use of instrumental variable while performing quantile regressions. Table 4 and 5 report the IV estimates of equation (1) where the dependent variable is the crude birth rate. Clearly, as distinct from Tables 2 and 3, we find that, for each model specification and quantile, the estimated coefficients of education on fertility are consistently smaller at higher than at lower quantile.

In Tables 4 and 5, interesting insights emerge on the variable effect of education on fertility when education is being instrumented by distance to Mainz. First, we observe that the effect of urbanization on fertility rates has moved from being negative but insignificant at lower quantile (column 4) to becoming positive and significant at higher quantile (for male). In comparison to the estimates at median quantile - where it was observed that at more densely populated environments fertility rates are significantly lower, whereas in more urbanized counties fertility rates are higher - in IV regression, the results seem consistent at $25^{\text {th }}$ quantile. The trend seems to get reversed and in some cases the effects disappear at higher quantile, depicting once again the necessity of using full distributional assumption than undertaking inference at only 'mean' based estimates. 
Table 2: Quantile regression results - education to fertility: Men

\begin{tabular}{|c|c|c|c|c|c|c|c|c|c|c|c|c|}
\hline \multirow{3}{*}{$\begin{array}{l}\text { Dependent } \\
\text { Variable }\end{array}$} & \multicolumn{12}{|c|}{ Crude Birth Rate } \\
\hline & \multicolumn{2}{|l|}{$(1)$} & \multirow[b]{2}{*}{$\tau=0.75$} & \multicolumn{2}{|l|}{$(2)$} & \multirow[b]{2}{*}{$\tau=0.75$} & \multicolumn{2}{|l|}{ (3) } & \multirow[b]{2}{*}{$\tau=0.75$} & \multirow[t]{2}{*}{ (4) } & \multirow[b]{2}{*}{$\tau=0.50$} & \multirow[b]{2}{*}{$\tau=0.75$} \\
\hline & $\tau=0.25$ & $\tau=0.50$ & & $\tau=0.25$ & $\tau=0.50$ & & $\tau=0.25$ & $\tau=0.50$ & & & & \\
\hline \multirow[t]{2}{*}{$\begin{array}{l}\text { Boys } \\
\text { enrollment }\end{array}$} & $-1.998 * * *$ & $\begin{array}{l}- \\
10.005^{* * *}\end{array}$ & $-7.774 * *$ & $-1.941 * * *$ & $\begin{array}{l}- \\
10.436 * * *\end{array}$ & $-9.801 * * *$ & $-2.153^{* * *}$ & $\begin{array}{l}- \\
11.330 * * *\end{array}$ & $\begin{array}{l}- \\
10.961 * * *\end{array}$ & $-1.125^{*}$ & $-6.708 * * *$ & $-7.880 * * *$ \\
\hline & (.613) & $(2.455)$ & $(2.496)$ & $(0.649)$ & $(2.651)$ & $(2.582)$ & (.649) & $(2.579)$ & $(2.573)$ & $(0.684)$ & $(2.521)$ & $(1.975)$ \\
\hline \multirow[t]{2}{*}{$\begin{array}{l}\text { Male in } \\
\text { agriculture }\end{array}$} & & & & $2.108^{* *}$ & 5.053 & -0.338 & $1.741^{*}$ & 3.503 & -2.349 & 1.302 & 1.660 & -3.517 \\
\hline & & & & $(1.043)$ & $(5.471)$ & $(4.337)$ & $(1.061)$ & $(5.508)$ & $(4.202)$ & $(0.846)$ & (4.198) & (3.817) \\
\hline \multirow[t]{2}{*}{$\begin{array}{l}\text { Male in } \\
\text { industry }\end{array}$} & & & & $2.583^{* *}$ & $12.040 * *$ & 2.014 & $2.578^{* *}$ & $12.018^{* * *}$ & 1.987 & 1.056 & 5.162 & -2.588 \\
\hline & & & & $(1.027)$ & $(4.781)$ & $(4.951)$ & $(0.997)$ & $(4.462)$ & $(5.117)$ & $(1.153)$ & $(4.080)$ & $(6.365)$ \\
\hline \multirow[t]{2}{*}{ Urbanization } & & & & $20.561^{* * *}$ & $83.342 * *$ & $130.658^{* *}$ & $13.754^{* *}$ & 54.622 & $93.411^{* *}$ & $10.476^{*}$ & 39.340 & $82.977^{* *}$ \\
\hline & & & & $(7.353)$ & $(37.846)$ & (41.879) & $(6.988)$ & $(37.590)$ & $(42.463)$ & $(5.890)$ & $(34.226)$ & $(40.870)$ \\
\hline \multirow[t]{2}{*}{$\begin{array}{l}\text { Population } \\
\text { density }\end{array}$} & & & & $-0.412 * *$ & $-1.686 * *$ & $-3.192 * * *$ & $-0.265^{*}$ & -1.066 & $-2.388 * *$ & $-0.248 * *$ & -0.992 & $-2.340 * *$ \\
\hline & & & & (0.159) & $(0.834)$ & $(0.927)$ & $(0.148)$ & $(0.820)$ & $(0.936)$ & $(0.126)$ & $(0.772)$ & (0.918) \\
\hline \multirow{2}{*}{$\begin{array}{l}\text { Share } \\
\text { Protestants }\end{array}$} & & & & & & & $0.043 * *$ & $0.184^{* *}$ & $0.239 * * *$ & 0.024 & 0.093 & $0.176 * *$ \\
\hline & & & & & & & $(0.016)$ & $(0.086)$ & $(0.070)$ & $(0.021)$ & $(0.087)$ & (0.070) \\
\hline \multirow[t]{2}{*}{$\begin{array}{l}\text { Life } \\
\text { expectancy }\end{array}$} & & & & & & & & & & $-0.144^{* *}$ & $-0.699 * * *$ & $-0.489 * * *$ \\
\hline & & & & & & & & & & $(0.028)$ & $(0.101)$ & $(0.110)$ \\
\hline \multirow[t]{2}{*}{ Constant } & $26.123 * * *$ & $31.832 * * *$ & $35.002 * * *$ & $24.211 * * *$ & $26.941 * * *$ & $35.674 * * *$ & $24.548 * * *$ & $28.363 * * *$ & $37.517 * * *$ & $30.031 * * *$ & $54.859 * * *$ & $56.023 * * *$ \\
\hline & $(.313)$ & (1.480) & (1.664) & (1.005) & (5.145) & (4.609) & (1.020) & (5.112) & $(4.462)$ & $(1.238)$ & (5.653) & (6.579) \\
\hline
\end{tabular}




\begin{tabular}{|c|c|c|c|c|c|c|c|c|c|c|c|c|}
\hline $\mathrm{N}$ & 86 & 86 & 86 & 86 & 86 & 86 & 86 & 86 & 86 & 85 & 85 & 85 \\
\hline $\mathrm{R}^{2}$ & 0.101 & 0.123 & 0.090 & 0.167 & 0.180 & 0.244 & 0.191 & 0.201 & 0.291 & 0.362 & 0.402 & 0.423 \\
\hline $\mathrm{F}$ & $10.62 * * *$ & $16.6 * * *$ & $9.70 * * *$ & $7.57^{* * *}$ & $19.61^{* * *}$ & $7.12^{* * *}$ & $7.18^{* * *}$ & $17.79 * * *$ & $11.08 * * *$ & $9.82 * * *$ & $37.78 * * *$ & $11.05^{* * *}$ \\
\hline
\end{tabular}

Note: Quantile regressions. Dependent variable: crude birth rate. Robust standard errors in parentheses. ${ }^{*} p<0.05$, ** $p<0.01$, *** $p<0.001$. Crude birth rate is defined as the number of birth (in $1000 \mathrm{~s}$ ) over the total population. Boys enrollment rate is the share of boys aged 6-14 enrolled in public primary schools.

Source: County-level data from the Statistique Générale de la France.

Table 3: Quantile regression results - education to fertility: Women

\begin{tabular}{|c|c|c|c|c|c|c|c|c|c|c|c|c|}
\hline \multirow{3}{*}{$\begin{array}{l}\text { Dependent } \\
\text { Variable }\end{array}$} & \multicolumn{12}{|c|}{ Crude Birth Rate } \\
\hline & (1) & & & $(2)$ & & & (3) & & & (4) & & \\
\hline & $\tau=0.25$ & $\tau=0.50$ & $\tau=0.75$ & $\tau=0.25$ & $\tau=0.50$ & $\tau=0.75$ & $\tau=0.25$ & $\tau=0.50$ & $\tau=0.75$ & $\tau=0.25$ & $\tau=0.50$ & $\tau=0.75$ \\
\hline \multirow[t]{2}{*}{$\begin{array}{l}\text { Girls } \\
\text { enrollment }\end{array}$} & $-1.594^{* *}$ & $-7.603 * * *$ & $-5.105 * * *$ & $-1.714^{* *}$ & $-8.895^{* * *}$ & $-7.371^{* * *}$ & $-1.778 * * *$ & $-9.136^{* * *}$ & $-7.700 * * *$ & -0.642 & $-3.926^{*}$ & $-4.142 * *$ \\
\hline & $(0.542)$ & $(2.252)$ & $(2.044)$ & $(0.549)$ & $(2.228)$ & (1.911) & $(0.540)$ & $(2.213)$ & $(1.866)$ & (0.599) & $(2.264)$ & $(1.453)$ \\
\hline \multirow[t]{2}{*}{$\begin{array}{l}\text { Female in } \\
\text { agriculture }\end{array}$} & & & & $1.467^{*}$ & 1.928 & -4.183 & 1.311 & 1.356 & -4.963 & 1.005 & 0.205 & -5.737 \\
\hline & & & & $(0.848)$ & $(4.258)$ & (3.922) & $(0.847)$ & $(4.269)$ & (3.379) & $(0.665)$ & (3.368) & (3.557) \\
\hline \multirow[t]{2}{*}{$\begin{array}{l}\text { Female in } \\
\text { industry }\end{array}$} & & & & $3.448 * *$ & $13.814 * * *$ & $0.245^{*}$ & $3.459 * *$ & $13.857 * * *$ & 0.303 & 1.601 & 5.583 & -5.335 \\
\hline & & & & (1.093) & $(5.486)$ & (4.035) & $(1.081)$ & (5.247) & (3.872) & (1.103) & $(4.226)$ & $(4.298)$ \\
\hline \multirow[t]{2}{*}{ Urbanization } & & & & $18.229 * * *$ & $75.696^{* *}$ & $119.843^{* *}$ & $12.925^{* *}$ & 55.631 & $92.474 * *$ & 4.985 & 18.543 & 67.118 \\
\hline & & & & $(6.428)$ & (36.11) & $(41.88)$ & $(5.902)$ & (35.123) & (42.018) & $(5.652)$ & (36.588) & $(43.667)$ \\
\hline \multirow[t]{2}{*}{$\begin{array}{l}\text { Population } \\
\text { density }\end{array}$} & & & & $-0.368 * * *$ & $-1.528^{*}$ & $-2.958 * *$ & $-0.248^{*}$ & -1.074 & $-2.339 * * *$ & -0.130 & -0.521 & $-1.961^{* *}$ \\
\hline & & & & $(0.142)$ & $(0.809)$ & $(0.934)$ & $(0.130)$ & $(0.787)$ & (0.939) & $(0.125)$ & $(0.825)$ & $(0.981)$ \\
\hline Share & & & & & & & $0.037^{* * *}$ & $0.142 *$ & $0.194 * * *$ & 0.016 & 0.040 & 0.124 \\
\hline
\end{tabular}


Protestants

$\begin{array}{llllll}(0.013) & (0.085) & (0.078) & (0.016) & (0.091) & (0.089)\end{array}$

Life

expectancy

$-0.141^{* * *} \quad-0.677^{* * *} \quad-0.463^{* * *}$

Constant

$25.609 * * * \quad 29.112 * * * \quad 32.609 * * *$

(0.024) (0.087) (0.138)

Constant

(2.044)

$24.474^{* * *} \quad 27.256^{* * *}$

$35.497 * * *$

$27.494 * * * \quad 35.822 * * *$

$30.300 * * * \quad 54.880 * * * \quad 54.568 * * *$

\section{$\mathrm{N}$}

$\mathrm{R}^{2}$

$\begin{array}{llllll}86 & 86 & 86 & 86 & 86 & 86 \\ 0.101 & 0.123 & 0.090 & 0.167 & 0.180 & 0.244 \\ 10.62^{* * *} & 16.6^{* * *} & 9.70^{* * *} & 7.57^{* * *} & 19.61^{* * *} & 7.12^{* * *}\end{array}$

86
0.191
$7.18 * * *$

86
0.201
$17.79 * * *$

$\begin{array}{llll}86 & 85 & 85 & 85 \\ 0.291 & 0.362 & 0.402 & 0.423 \\ 11.08 * * * & 9.82 * * * & 37.78^{* * *} & 11.05^{* * *}\end{array}$

Note: Quantile regressions. Dependent variable: crude birth rate. Robust standard errors in parentheses. ${ }^{*} p<0.05, * * p<0.01, * * * p<0.001$. Crude birth rate is defined as the number of birth (in $1000 \mathrm{~s}$ ) over the total population. Girls enrollment rate is the share of girls aged 6-14 enrolled in public primary schools.

Source: County-level data from the Statistique Générale de la France.

Table 4: IV Quantile regression results - education to fertility: Men

\begin{tabular}{|c|c|c|c|c|c|c|c|c|c|c|c|c|}
\hline \multirow{3}{*}{$\begin{array}{l}\text { Dependent } \\
\text { Variable }\end{array}$} & \multicolumn{12}{|c|}{ Crude Birth Rate } \\
\hline & (1) & & & (2) & & & (3) & & & (4) & & \\
\hline & $\tau=0.25$ & $\tau=0.50$ & $\tau=0.75$ & $\tau=0.25$ & $\tau=0.50$ & $\tau=0.75$ & $\tau=0.25$ & $\tau=0.50$ & $\tau=0.75$ & $\tau=0.25$ & $\tau=0.50$ & $\tau=0.75$ \\
\hline \multirow[t]{2}{*}{$\begin{array}{l}\text { Boys } \\
\text { enrollment }\end{array}$} & $-4.533^{* *}$ & $-4.463 * * *$ & $\begin{array}{l}- \\
10.041^{* *} \\
*\end{array}$ & $-3.250 * *$ & $-4.137 * * *$ & $-9.762 * * *$ & $-3.280^{*}$ & $-4.167 * * *$ & $-9.529 * * *$ & $-6.677^{* * *}$ & $-6.743 * * *$ & $-7.859 * * *$ \\
\hline & $(2.307)$ & $(1.066)$ & (1.161) & $(1.782)$ & $(0.020)$ & $(2.288)$ & (1.698) & $(0.020)$ & $(2.482)$ & (1.941) & $(1.776)$ & $(2.648)$ \\
\hline \multirow[t]{2}{*}{$\begin{array}{l}\text { Male in } \\
\text { agriculture }\end{array}$} & & & & $7.777^{*}$ & 4.827 & 2.979 & $11.740 * * *$ & $5.756 *$ & 0.596 & $9.776^{* * *}$ & $\begin{array}{l}17.430 * * \\
*\end{array}$ & 2.109 \\
\hline & & & & $(4.413)$ & (3.667) & (3.188) & $(4.702)$ & (3.066) & $(4.261)$ & (3.859) & (7.264) & (3.676) \\
\hline
\end{tabular}




\begin{tabular}{|c|c|c|c|c|c|c|c|c|c|c|c|c|}
\hline $\begin{array}{l}\text { Male in } \\
\text { industry }\end{array}$ & & & & $\begin{array}{l}14.469 * \\
(7.970)\end{array}$ & $\begin{array}{l}6.121 \\
(6.117)\end{array}$ & $\begin{array}{l}4.949 \\
(7.020)\end{array}$ & $\begin{array}{l}14.269 * \\
(8.496)\end{array}$ & $\begin{array}{l}7.112 \\
(6.003)\end{array}$ & $\begin{array}{l}2.098 \\
(7.601)\end{array}$ & $\begin{array}{l}-1.853 \\
(5.950)\end{array}$ & $\begin{array}{l}-8.964 \\
(6.281)\end{array}$ & $\begin{array}{l}12.528 * * \\
* \\
(5.017)\end{array}$ \\
\hline $\begin{array}{l}\text { Urbanizatio } \\
n\end{array}$ & & & & $\begin{array}{l}103.513^{*} \\
* \\
(44.141)\end{array}$ & $\begin{array}{l}63.360 * * \\
(32.513)\end{array}$ & $\begin{array}{l}83.544^{* *} \\
(30.343)\end{array}$ & $\begin{array}{l}121.726 * * \\
* \\
(48.729)\end{array}$ & $\begin{array}{l}70.332 * * \\
(34.722)\end{array}$ & $\begin{array}{l}42.225^{*} \\
(24.672)\end{array}$ & $\begin{array}{l}-3.083 \\
(32.926)\end{array}$ & $\begin{array}{l}39.537^{*} \\
(21.443)\end{array}$ & $\begin{array}{l}35.038 * \\
(21.757)\end{array}$ \\
\hline $\begin{array}{l}\text { Population } \\
\text { density }\end{array}$ & & & & $\begin{array}{l}-5.004 * * * \\
(2.788)\end{array}$ & $\begin{array}{l}-1.283^{*} \\
(0.735)\end{array}$ & $\begin{array}{l}-1.939 * * \\
(0.680)\end{array}$ & $\begin{array}{l}-3.367 \\
(3.027)\end{array}$ & $\begin{array}{l}-1.409 * \\
(0.782)\end{array}$ & $\begin{array}{l}-1.887 \\
(2.671)\end{array}$ & $\begin{array}{l}-1.385 \\
(2.049)\end{array}$ & $\begin{array}{l}-0.206 \\
(1.875)\end{array}$ & $\begin{array}{l}-1.812 \\
(2.026)\end{array}$ \\
\hline $\begin{array}{l}\text { Share } \\
\text { Protestants }\end{array}$ & & & & & & & $\begin{array}{l}0.098 \\
(0.132)\end{array}$ & $\begin{array}{l}0.161^{*} \\
(0.088)\end{array}$ & $\begin{array}{l}0.169 * \\
(0.095)\end{array}$ & $\begin{array}{l}0.083 \\
(0.089)\end{array}$ & $\begin{array}{l}0.003 \\
(0.082)\end{array}$ & $\begin{array}{l}0.086^{*} \\
(0.052)\end{array}$ \\
\hline $\begin{array}{l}\text { Life } \\
\text { expectancy }\end{array}$ & & & & & & & & & & $\begin{array}{l}-0.532 * * * \\
(0.095)\end{array}$ & $\begin{array}{l}-0.649 * * * \\
(0.101)\end{array}$ & $\begin{array}{l}-0.508 * * * \\
(0.093)\end{array}$ \\
\hline Constant & $\begin{array}{l}26.906 * * \\
* \\
(1.273)\end{array}$ & $\begin{array}{l}29.172^{* *} \\
* \\
(0.541)\end{array}$ & $\begin{array}{l}34.587^{* *} \\
* \\
(0.590)\end{array}$ & $\begin{array}{l}21.149 * * \\
* \\
(4.636)\end{array}$ & $\begin{array}{l}24.801 * * \\
* \\
(3.113)\end{array}$ & $\begin{array}{l}31.018 * * \\
* \\
(4.083)\end{array}$ & $\begin{array}{l}13.850 * * * \\
(4.450)\end{array}$ & $\begin{array}{l}23.426 * * \\
* \\
(3.067)\end{array}$ & $\begin{array}{l}33.955^{* *} \\
* \\
(3.328)\end{array}$ & $\begin{array}{l}48.184^{* *} \\
* \\
(5.038)\end{array}$ & $\begin{array}{l}47.726 * * \\
* \\
(4.610)\end{array}$ & $\begin{array}{l}49.964 * * \\
* \\
(5.170)\end{array}$ \\
\hline$N$ & 86 & 86 & 86 & 86 & 86 & 86 & 86 & 86 & 86 & 85 & 85 & 85 \\
\hline$R^{2}$ & 0.112 & 0.129 & 0.107 & 0.174 & 0.184 & 0.231 & 0.202 & 0.240 & 0.301 & 0.379 & 0.425 & 0.410 \\
\hline $\mathrm{F}$ & $12.35^{* * *}$ & $16.87 * * *$ & $10.66 * * *$ & $9.36 * * *$ & $19.55^{* * *}$ & $8.19 * * *$ & $7.68^{* * *}$ & $17.98 * * *$ & $12.01 * * *$ & $9.83 * * *$ & $38.98 * * *$ & $11.56 * * *$ \\
\hline
\end{tabular}

Note: Instrumental variable quantile regressions. Dependent variable: crude birth rate. Robust standard errors in parentheses. ${ }^{*} p<0.05, * * p<0.01, * * * p<0.001$. Crude birth rate is defined as the number of birth (in $1000 \mathrm{~s}$ ) over the total population. Boys enrollment rate is the share of boys aged 6-14 enrolled in public primary schools. Instrument for enrollment rate is Distance to Mainz. The instrument has been chosen from a set of comparative indicators based on overidentification test.

Source: County-level data from the Statistique Générale de la France. 
Table 5: IV Quantile regression results - education to fertility: Women

\begin{tabular}{|c|c|c|c|c|c|c|c|c|c|c|c|c|}
\hline \multirow{3}{*}{$\begin{array}{l}\text { Dependent } \\
\text { Variable }\end{array}$} & \multicolumn{12}{|c|}{ Crude Birth Rate } \\
\hline & \multicolumn{3}{|l|}{ (1) } & \multicolumn{3}{|l|}{$(2)$} & \multicolumn{3}{|l|}{ (3) } & \multicolumn{3}{|l|}{ (4) } \\
\hline & $\tau=0.25$ & $\tau=0.50$ & $\tau=0.75$ & $\tau=0.25$ & $\tau=0.50$ & $\tau=0.75$ & $\tau=0.25$ & $\tau=0.50$ & $\tau=0.75$ & $\tau=0.25$ & $\tau=0.50$ & $\tau=0.75$ \\
\hline \multirow[t]{2}{*}{$\begin{array}{l}\text { Girls } \\
\text { enrollment }\end{array}$} & $-3.233 * *$ & $5.552 * * *$ & $-9.692 * * *$ & $-6.707 * *$ & $-7.952 * * *$ & $\begin{array}{l}- \\
10.062^{* * *}\end{array}$ & $-5.223 * *$ & $-7.466 * * *$ & $-9.160 * * *$ & -5.736 & $-8.859 * *$ & $-9.572 *$ \\
\hline & (1.91) & $(2.479)$ & $(2.816)$ & (2.949) & $(2.503)$ & $(3.022)$ & $(2.653)$ & $(2.763)$ & $(2.986)$ & $(2.352)$ & $(2.350)$ & $(2.512)$ \\
\hline \multirow[t]{2}{*}{$\begin{array}{l}\text { Female in } \\
\text { agriculture }\end{array}$} & & & & 0.186 & 2.357 & -1.233 & 0.034 & 3.104 & -0.934 & 2.162 & -2.370 & -0.437 \\
\hline & & & & $(3.725)$ & $(3.431)$ & $(3.816)$ & $(3.353)$ & $(3.811)$ & (3.738) & (3.209) & $(2.636)$ & (2.819) \\
\hline \multirow[t]{2}{*}{$\begin{array}{l}\text { Female in } \\
\text { industry }\end{array}$} & & & & $14.355^{* *}$ & $11.446 * * *$ & 5.838 & $12.400 * *$ & $10.718^{* *}$ & 3.806 & $14.018 * *$ & 1.159 & -0.153 \\
\hline & & & & (6.928) & $(4.862)$ & (9.203) & $(5.356)$ & (5.590) & (9.053) & (7.140) & (6.607) & (7.065) \\
\hline \multirow[t]{2}{*}{ Urbanization } & & & & $72.608^{*}$ & $58.786^{*}$ & 30.082 & $59.245^{*}$ & $57.088^{*}$ & 21.346 & $-42.442 * *$ & -4.534 & 26.184 \\
\hline & & & & $(42.55)$ & (32.049) & (43.595) & $(34.745)$ & $(35.350)$ & (43.138) & $(20.843)$ & (31.173) & (33.333) \\
\hline \multirow[t]{2}{*}{$\begin{array}{l}\text { Population } \\
\text { density }\end{array}$} & & & & -1.549 & -1.587 & -1.881 & -0.554 & -1.107 & 0.072 & $3.693 * *$ & -0.076 & 4.876 \\
\hline & & & & (2.796) & $(2.240)$ & (2.865) & $(2.325)$ & $(2.546)$ & $(2.844)$ & (1.764) & $(2.031)$ & (1.979) \\
\hline \multirow{2}{*}{$\begin{array}{l}\text { Share } \\
\text { Protestants }\end{array}$} & & & & & & & 0.100 & $0.145^{*}$ & 0.061 & $0.131 * *$ & 0.039 & -0.077 \\
\hline & & & & & & & $(0.100)$ & $(0.090)$ & $(0.120)$ & $(0.092)$ & $(0.085)$ & $(0.104)$ \\
\hline \multirow[t]{2}{*}{$\begin{array}{l}\text { Life } \\
\text { expectancy }\end{array}$} & & & & & & & & & & $-0.428 * * *$ & $-0.628 * * *$ & $-0.429 * * *$ \\
\hline & & & & & & & & & & (0.107) & (0.089) & (0.099) \\
\hline \multirow[t]{2}{*}{ Constant } & $25.542 * * *$ & 28.812 & $32.958 * * *$ & $26.109 * * *$ & $27.367^{* * *}$ & $34.378 * * *$ & $24.985^{* * *}$ & $26.184 * * *$ & $32.372 * * *$ & $42.196 * * *$ & $52.850 * * *$ & $47.471 * * *$ \\
\hline & $(0.948)$ & $(0.858)$ & (0.975) & (3.445) & (3.258) & (3.530) & (3.009) & (3.701) & (3.504) & (4.508) & (4.281) & (4.577) \\
\hline
\end{tabular}




\begin{tabular}{|c|c|c|c|c|c|c|c|c|c|c|c|c|}
\hline $\mathrm{N}$ & 86 & 86 & 86 & 86 & 86 & 86 & 86 & 86 & 86 & 85 & 85 & 85 \\
\hline $\mathrm{R}^{2}$ & 0.100 & 0.125 & 0.102 & 0.184 & 0.210 & 0.201 & 0.187 & 0.201 & 0.307 & 0.354 & 0.442 & 0.406 \\
\hline $\mathrm{F}$ & $11.34^{* * *}$ & $16.9 * * *$ & $9.88 * * *$ & $8.74 * * *$ & $16.32 * * *$ & $8.90 * * *$ & $7.68 * * *$ & $16.22 * * *$ & $12.21 * * *$ & $10.02 * * *$ & $31.61 * * *$ & $11.80 * * *$ \\
\hline
\end{tabular}

Note: Instrumental variable quantile regressions. Dependent variable: crude birth rate. Robust standard errors in parentheses. $* p<0.05, * * p<0.01, * * * p<0.001$.

Crude birth rate is defined as the number of birth (in $1000 \mathrm{~s}$ ) over the total population. Girls enrollment rate is the share of girls aged 6-14 enrolled in public primary schools. Instrument for enrollment rate is Distance to Mainz. The instrument has been chosen from a set of comparative indicators based on overidentification test.

Source: County-level data from the Statistique Générale de la France. 


\subsection{Short-run Effects: From Fertility to Education}

The discussion of results in the preceding section focused on education-fertility channel with the relationship running from education to fertility. To further qualify evidence on qualityquantity hypothesis, we present, in this section, results by considering reverse causality, i.e., from fertility to education. Tables 6 and 7 report Instrumental variable quantile regression estimates of the education equation (2), where boys and girls enrollment rates are each in turn function of the crude birth rate. Unlike the education-fertility channel, we do not present here the Quantile regression results without treatment of endogeneity bias, as we have argued before that possible endogeneity can plague OLS or quantile estimates. Hence, we are inclined to present only IV quantile estimates. The reason for undertaking reverse causality has been stated earlier; however, at this point we should note that we are not interested in testing causality of quantity-quality trade-off hypothesis. This can be an interesting exercise which we reserve for future research. In what we present in terms of estimation strategy of the trade-off is the observed empirical approaches undertaken in the extant literature (e.g. Becker et al., 2010).

Accordingly, following the reverse form of causality ${ }^{10}$, the school enrollment rate is the dependent variable and the crude birth rate is our variable of interest. To treat possibility of endogeneity of fertility with other regressors, we have instrumented crude birth rate with adult sex ratio. Tables 6 and 7 report the estimates where boys and girls enrollment rates are each in turn function of the crude birth rate. Column 1 displays the estimation results without any control variables. Models 2 to 4 report estimation results adding different set of control variables. As before, we present estimates for three quantiles $\left(25^{\text {th }}, 50^{\text {th }}\right.$, and $\left.75^{\text {th }}\right)$. Regardless the specification and distribution of heterogeneity, the coefficient of fertility is significant and negative at least at the $1 \%$ level which confirms the significant and robust association from fertility to education.

\footnotetext{
${ }^{10}$ Test of causality in cross-sectional regression of the type we have presented in this article can be performed either by matching or by spatial causality test. We reserved this for future research.
} 
Tables 6 and 7 present interesting findings with respect to Instrumental variable quantile regressions. Overall results indicate stronger effects of fertility decline on the likelihood of female empowerment with respect to education. Both at $50^{\text {th }}$ and $25^{\text {th }}$ quantile, Tables 6 and 7 (without introduction of controls, i.e., the restricted model) clearly show that fertility decline exerted greater effects on girls' enrollment rate that on boys' enrollment rate. Of course, when controlling for the role of men and women in agriculture and industry, as well as the effect of urbanization and population density (model 2 in Table 6 and 7), the results yet point at the larger role of women, than men. Our interquartile difference test for menwomen differences in results in each quantile also rejects the null hypothesis of no significant effect in favor of greater effects of women (at $5 \%$ levels: results not reported here). Moreover, a striking result merits attention: while urbanization seems to have exerted significant effect on boys' enrollment, while controlling for fertility, the same variable does not appear to affect girls' enrollment at all. ${ }^{11}$ Contrastingly, those women who might have already been residing in urban environment are found to experience a boost toward enrollment in public primary schools by participating in industry work. In addition, higher life-expectancy for women had larger positive and significant effects on the enrollment rates than the life expectancy of men for all quantiles. Conversely, higher share of Protestants had positive and significant effects on the propensity to invest in boys' enrollment rates (at $25^{\text {th }}$ and $75^{\text {th }}$ quantiles in Table 6); but not to invest in girls' education.

The estimates of equation (1) and equation (2) confirm the existence of a mutual negative and significant relationship between fertility and education, supporting the existence of a child quantity-quality trade-off in 1851 France. Hence, counties in which the increase in education has been more important account for larger changes in fertility, and conversely. These results are coherent with the interpretation of the unified growth theory (Galor and Moav, 2002; Galor, 2005; Diebolt and Perrin, 2013; 2019a,b). Yet, the decisions about quality and quantity of children being taken simultaneously, the analysis does not allow us to conclude about the causality between education and fertility.

\footnotetext{
${ }^{11}$ This result might be due to the fact that urbanization often motivates the migration of men workers more than the migration of women, rightly so in the historical episodes this study is based on.
} 
Table 6: IV Quantile regression results - fertility to education: Men

\begin{tabular}{|c|c|c|c|c|c|c|c|c|c|c|c|c|}
\hline \multirow{3}{*}{$\begin{array}{l}\text { Dependent } \\
\text { Variable }\end{array}$} & \multicolumn{12}{|c|}{ Boys enrollment rate } \\
\hline & \multicolumn{3}{|l|}{$(1)$} & \multicolumn{3}{|l|}{$(2)$} & \multicolumn{3}{|l|}{ (3) } & \multicolumn{3}{|l|}{ (4) } \\
\hline & $\tau=0.25$ & $\tau=0.50$ & $\tau=0.75$ & $\tau=0.25$ & $\tau=0.50$ & $\tau=0.75$ & $\tau=0.25$ & $\tau=0.50$ & $\tau=0.75$ & $\tau=0.25$ & $\tau=0.50$ & $\tau=0.75$ \\
\hline \multirow[t]{2}{*}{ Crude Birth Rate } & $-0.017 * * *$ & $-0.015^{* *}$ & $-0.039 * *$ & $-0.017 * * *$ & $-0.019 * *$ & $-0.038 * *$ & $-0.017 * * *$ & $-0.023 * * *$ & $-0.043 * * *$ & $-0.015^{* *}$ & $-0.021 * *$ & $-0.058 * *$ \\
\hline & $(0.004)$ & $(0.007)$ & $(0.014)$ & $(0.004)$ & $(0.008)$ & $(0.012)$ & $(0.003)$ & $(0.008)$ & $(0.010)$ & $(0.005)$ & $(0.009)$ & $(0.018)$ \\
\hline \multirow[t]{2}{*}{ Male in agriculture } & & & & -0.006 & -0.101 & -0.222 & -0.040 & -0.134 & -0.312 & -0.069 & -0.133 & -0.584 \\
\hline & & & & $(0.187)$ & $(0.190)$ & $(0.322)$ & $(0.161)$ & $(0.222)$ & $(0.336)$ & (0.159) & $(0.201)$ & $(0.360)$ \\
\hline \multirow[t]{2}{*}{ Male in industry } & & & & 0.315 & 0.331 & 0.095 & 0.379 & 0.332 & 0.041 & 0.398 & 0.319 & -0.468 \\
\hline & & & & $(0.388)$ & $(0.578)$ & (0.669) & $(0.388)$ & $(0.601)$ & $(0.596)$ & $(0.403)$ & $(0.602)$ & $(0.760)$ \\
\hline \multirow[t]{2}{*}{ Urbanization } & & & & 3.015 & $5.576^{* *}$ & $6.425 * *$ & 1.222 & $4.569 * *$ & 0.443 & 0.975 & 3.096 & 2.718 \\
\hline & & & & $(2.552)$ & $(2.841)$ & (3.229) & $(2.344)$ & (2.369) & $(2.369)$ & (2.059) & $(2.553)$ & (3.150) \\
\hline \multirow[t]{2}{*}{ Population density } & & & & -0.075 & -0.136 & -0.163 & -0.031 & -0.113 & -0.026 & -0.025 & -0.078 & -0.096 \\
\hline & & & & $(0.087)$ & $(0.122)$ & (0.157) & $(0.085)$ & $(0.123)$ & $(0.173)$ & $(0.087)$ & $(0.131)$ & $(0.156)$ \\
\hline \multirow[t]{2}{*}{ Share Protestants } & & & & & & & $0.009 *$ & 0.007 & $0.018 * * *$ & $0.010 * *$ & 0.007 & $0.015^{* *}$ \\
\hline & & & & & & & $(0.005)$ & $(0.006)$ & $(0.007)$ & $(0.004)$ & $(0.005)$ & $(0.006)$ \\
\hline \multirow[t]{2}{*}{ Life expectancy } & & & & & & & & & & 0.002 & 0.0009 & -0.021 \\
\hline & & & & & & & & & & $(0.005)$ & $(0.008)$ & $(0.016)$ \\
\hline \multirow[t]{2}{*}{ Constant } & $0.850 * * *$ & $0.923 * * *$ & $1.733 * * *$ & $0.854 * * *$ & $1.053 * * *$ & $1.864 * * *$ & $0.873 * * *$ & $1.163^{* * *}$ & $2.060 * * *$ & $0.739 * *$ & $1.079 * *$ & $3.623^{* * *}$ \\
\hline & $(0.115)$ & $(0.232)$ & $(0.395)$ & $(0.228)$ & $(0.282)$ & $(0.338)$ & (0.229) & $(0.330)$ & $(0.378)$ & $(0.343)$ & $(0.542)$ & $(0.988)$ \\
\hline $\mathrm{N}$ & 86 & 86 & 86 & 86 & 86 & 86 & 86 & 86 & 86 & 85 & 85 & 85 \\
\hline $\mathrm{R}^{2}$ & 0.100 & 0.125 & 0.102 & 0.173 & 0.147 & 0.195 & 0.217 & 0.174 & 0.238 & 0.221 & 0.176 & 0.232 \\
\hline $\mathrm{F}$ & $11.34 * * *$ & $16.9 * * *$ & $9.88 * * *$ & $9.39 * * *$ & $74.20 * * *$ & $28.73 * * *$ & $3.60 * *$ & $16.22 * * *$ & $12.21 * * *$ & $10.59 * * *$ & $38.22 * * *$ & $12.56 * * *$ \\
\hline
\end{tabular}

Note: Instrumental variable quantile regressions. Dependent variable: crude birth rate. Robust standard errors in parentheses. ${ }^{*} p<0.05, * * p<0.01,{ }^{* * *} p<0.001$. Crude birth rate is defined as the number of birth (in $1000 \mathrm{~s}$ ) over the total population. Boys enrollment rate is the share of boys aged 6-14 enrolled in public primary schools. Instrument for CBR is Adult sex ratio. The instrument has been chosen from a set of comparative indicators based on overidentification test. Source: County-level data from the Statistique Générale de la France. 
Table 7: IV Quantile regression results - fertility to education: Women

\begin{tabular}{|c|c|c|c|c|c|c|c|c|c|c|c|c|}
\hline \multirow{3}{*}{ Dependent Variable } & \multicolumn{12}{|c|}{ Girls enrollment rate } \\
\hline & \multicolumn{3}{|l|}{ (1) } & \multicolumn{3}{|l|}{$(2)$} & \multicolumn{3}{|l|}{ (3) } & \multicolumn{3}{|l|}{ (4) } \\
\hline & $\tau=0.25$ & $\tau=0.50$ & $\tau=0.75$ & $\tau=0.25$ & $\tau=0.50$ & $\tau=0.75$ & $\tau=0.25$ & $\tau=0.50$ & $\tau=0.75$ & $\tau=0.25$ & $\tau=0.50$ & $\tau=0.75$ \\
\hline \multirow[t]{2}{*}{ Crude Birth Rate } & $-0.020 * *$ & $-0.018 * *$ & $-0.022 *$ & $-0.02 * *$ & $-0.020 * * *$ & $-0.024 * *$ & $-0.021 * * *$ & $-0.021 * * *$ & $-0.026 * * *$ & $-0.019 * *$ & $-0.025^{* *}$ & $-0.051 * *$ \\
\hline & $(0.006)$ & $(0.011)$ & $(0.005)$ & $(0.005)$ & $(0.010)$ & $(0.005)$ & $(0.005)$ & $(0.010)$ & $(0.004)$ & $(0.009)$ & $(0.017)$ & $(0.006)$ \\
\hline \multirow[t]{2}{*}{$\begin{array}{l}\text { Female in } \\
\text { agriculture }\end{array}$} & & & & $-0.277^{*}$ & $-0.300 * *$ & $-0.501 * *$ & $-0.282^{*}$ & $-0.307 * *$ & $-0.528 * *$ & $-0.230 * *$ & $-0.253^{* *}$ & $-0.412^{*}$ \\
\hline & & & & $(0.126)$ & $(0.255)$ & $(0.162)$ & $(0.128)$ & $(0.259)$ & $(0.101)$ & $(0.124)$ & $(0.246)$ & $(0.126)$ \\
\hline \multirow[t]{2}{*}{ Female in industry } & & & & $0.584 * *$ & $0.569 * *$ & 0.114 & $0.583 * *$ & $0.568 * *$ & 0.110 & $0.682 * *$ & $0.668 * *$ & $0.306 *$ \\
\hline & & & & $(0.276)$ & $(0.430)$ & $(0.248)$ & $(0.274)$ & $(0.429)$ & $(0.234)$ & $(0.263)$ & $(0.169)$ & $(0.276)$ \\
\hline \multirow[t]{2}{*}{ Urbanization } & & & & 1.532 & 2.279 & 3.670 & 1.268 & 1.963 & 2.390 & 1.327 & 2.024 & 2.520 \\
\hline & & & & $(2.152)$ & $(3.712)$ & $(2.025)$ & $(2.152)$ & $(3.128)$ & $(2.156)$ & $(2.307)$ & $(3.259)$ & $(2.152)$ \\
\hline \multirow[t]{2}{*}{ Population density } & & & & -0.044 & -0.061 & -0.099 & -0.038 & -0.054 & -0.069 & -0.034 & -0.050 & -0.063 \\
\hline & & & & $(0.048)$ & $(0.084)$ & $(0.045)$ & $(0.048)$ & $(0.070)$ & $(0.048)$ & $(0.051)$ & $(0.073)$ & $(0.048)$ \\
\hline \multirow[t]{2}{*}{ Share Protestants } & & & & & & & 0.002 & 0.002 & 0.009 & 0.002 & 0.002 & 0.010 \\
\hline & & & & & & & $(0.005)$ & $(0.101)$ & $(0.004)$ & $(0.004)$ & $(0.008)$ & $(0.005)$ \\
\hline \multirow[t]{2}{*}{ Life expectancy } & & & & & & & & & & $0.012 * *$ & $0.012 * *$ & $0.020 * *$ \\
\hline & & & & & & & & & & $(0.005)$ & $(0.009)$ & $(0.005)$ \\
\hline \multirow[t]{2}{*}{ Constant } & $0.792 * * *$ & $0.902 * * *$ & $1.139 * * *$ & $0.961^{* * *}$ & $1.101^{* * *}$ & $1.493 * * *$ & $0.972 * * *$ & $1.116^{* * *}$ & $1.554 * * *$ & $0.878 * *$ & $0.272 * *$ & $0.987 * *$ \\
\hline & $(0.181)$ & $(0.186)$ & $(0.333)$ & (0.193) & $(0.369)$ & $(0.338)$ & $(0.193)$ & $(0.195)$ & $(0.365)$ & $(0.349)$ & $(0.110)$ & $(0.419)$ \\
\hline $\mathrm{N}$ & 86 & 86 & 86 & 86 & 86 & 86 & 86 & 86 & 86 & 85 & 85 & 85 \\
\hline $\mathrm{R}^{2}$ & 0.100 & 0.114 & 0.09 & 0.213 & 0.240 & 0.125 & 0.219 & 0.243 & 0.140 & 0.247 & 0.268 & 0.109 \\
\hline $\mathrm{F}$ & $9.84 * *$ & $7.94 * *$ & $3.63^{*}$ & $12.11^{* * *}$ & $4.12^{* *}$ & $3.60 * *$ & $10.00 * *$ & $7.87^{* * *}$ & $3.40 * *$ & $8.25^{* * *}$ & $6.60 * * *$ & $4.99 * * *$ \\
\hline
\end{tabular}

Note: Instrumental variable quantile regressions. Dependent variable: crude birth rate. Robust standard errors in parentheses. ${ }^{*} p<0.05,{ }^{* *} p<0.01,{ }^{* * *} p<0.001$. Crude birth rate is defined as the number of birth (in $1000 \mathrm{~s}$ ) over the total population. Girls enrollment rate is the share of girls aged 6-14 enrolled in public primary schools. Instrument for CBR is Adult sex ratio. The instrument has been chosen from a set of comparative indicators based on overidentification test. Source: County-level data from the Statistique Générale de la France. 


\subsection{Longer run Effect of Human Capital on Fertility Transition}

From the study of the short-run relationship between education and fertility, our results show that the correlation goes in both directions of causation. This suggests the existence of a child quantity-quality trade-off in France during the French demographic transition. However, these results may hide a more complex underlying relationship, as advanced by Diebolt and Perrin (2019a). Henceforth, we test in this section the hypothesis that women endowments in human capital affect their own choices of fertility, and subsequently that of future generations. The objective of this study is then to determine whether the endowments in human capital in time $t$ affect the level of fertility in period $t+1$.

This motivates us to model the long-run effect of investment in human capital on fertility. We empirically test the effect of the percentage change in human capital investments between 1856 and 1870 on the variations in fertility between 1881 and 1911 across French counties. The motivation of such choice of data is to account for the effect of education on several generations of individuals (parents and grand-parents).

Figures $3 \mathrm{a}$ and $3 \mathrm{~b}$ give us an insight on the geographical distribution of changes in male and female literacy rates between 1856 and 1870, while Figure 3c provides an insight of the subsequent changes in crude birth rates, in particular between 1881 and 1911. Contrary to the agricultural and rural areas, the most industrialized area of France (Northeast) display lower variations in female literacy rates over the period studied. Comparatively, we see that counties experiencing stronger improvement in female literacy rates over the period 18561870 tend also to experience a steeper fertility decline (measured by the percentage change in crude birth rate over the period 1881-1911). 
Figure 3: Geographical Distribution of the Percentage Change in Education and Fertility

(3a) Male Human Capital, 1856-70

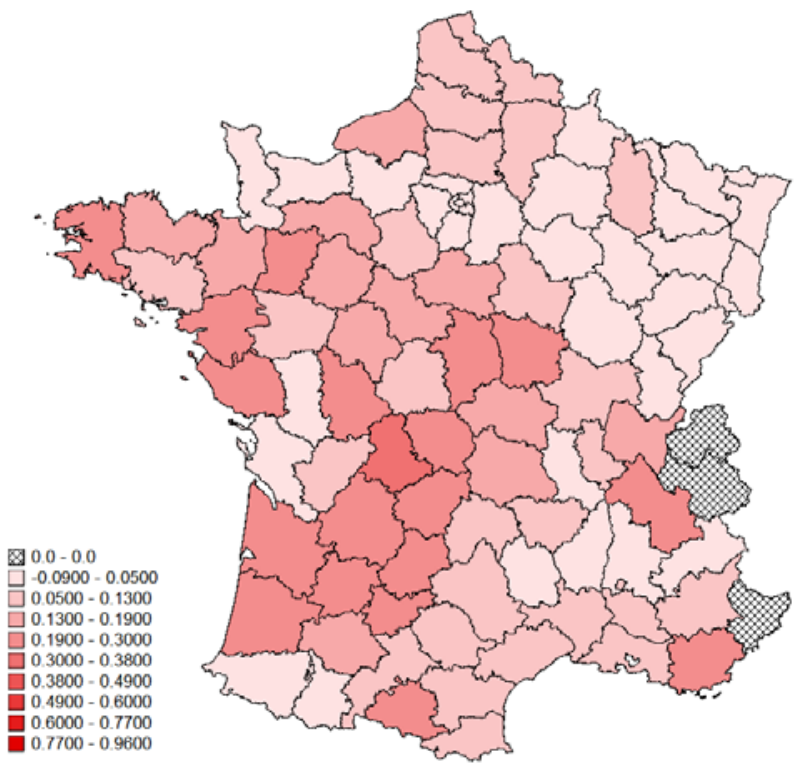

(3b) Female Human Capital, 1856-70

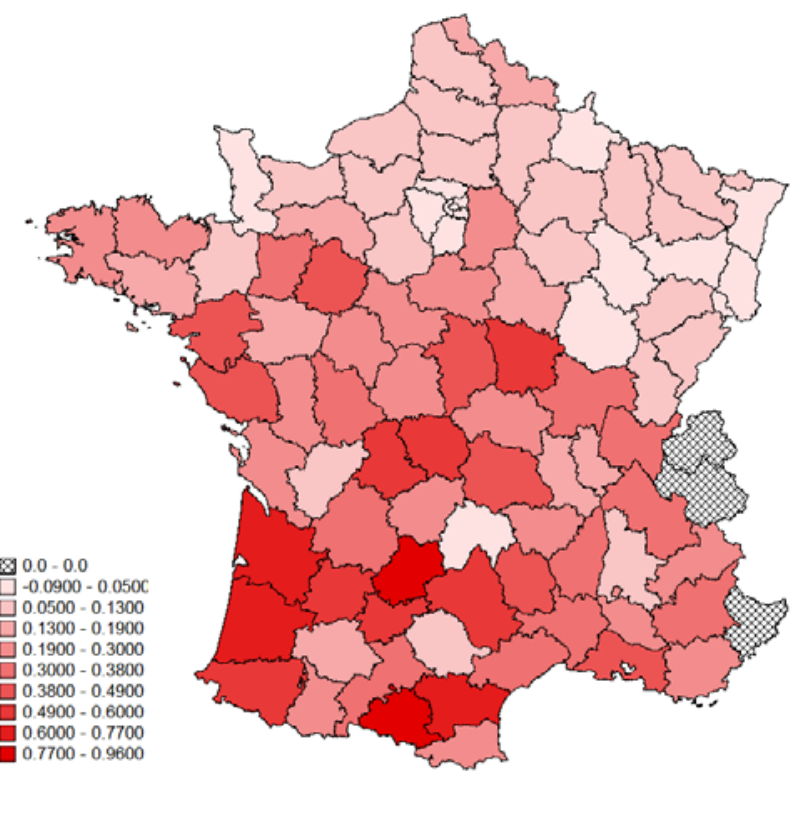

(3c) Crude Birth Rate, 1881-1911

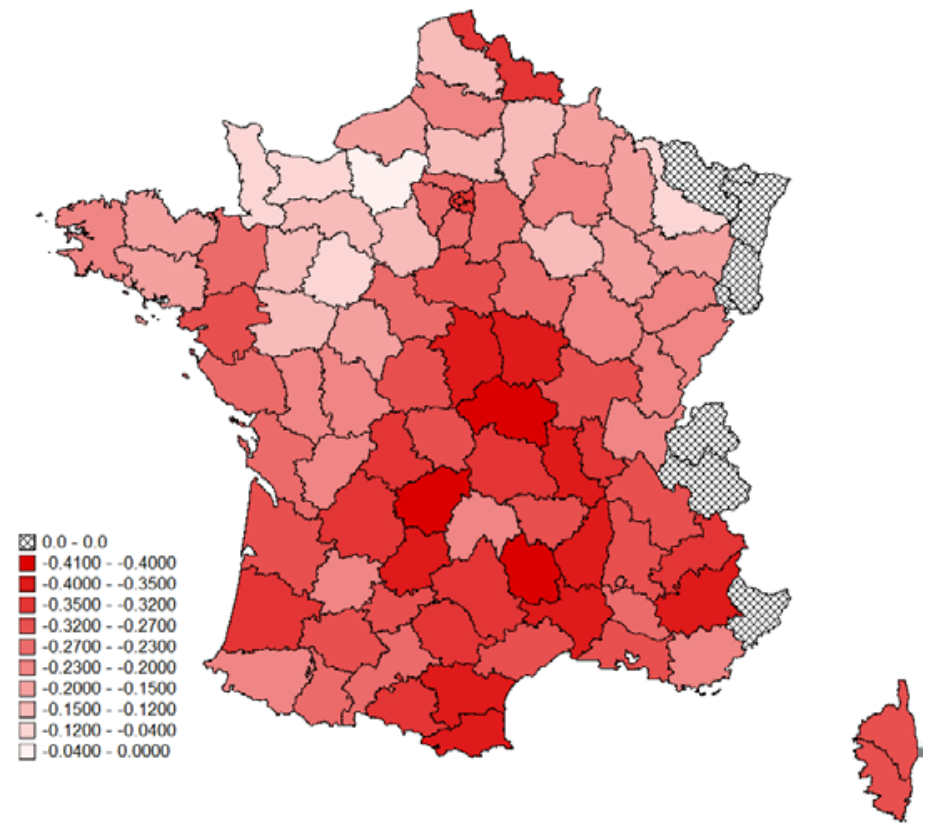

Sources: Using data from Statistique Générale de la France - Enseignement Primaire; Census

We estimate equation (3) using quantile regressions. We use various specifications to study how male and female endowments in human capital affect their future fertility, introducing successively the following covariates: (i) the crude birth rate in 1851; (ii) proxies for the level 
of industrialization specified as the level of urbanization and the population density; (iii) employment opportunities measured by the share of people making their living of agriculture and the share of people employed in manufacturing; (iv) the share of Protestants; $(v)$ the life expectancy at age 0 ; and (vi) the crude birth rate in 1881.

\section{Long-run estimates}

Tables 8 and 9 report the estimation results on the hypothesis that increasing educational investments have played a significant role in the fertility transition. Models 1 to 4 present various specifications of equation (3) for boys (Table 8 ) and girls (Table 9). Hence, we control for socio-economic factors adding successively control variables for employment opportunities and urbanization (model 1), religion (model 2), life expectancy (model 3) and crude birth rate in 1881 (model 4). ${ }^{12}$

We find very interesting results from a gendered perspective. The Quantile estimates show that the percentage change in literacy rates is negatively associated with the fertility transition. This result is strongly significant for women only. This result is in line with Diebolt and Perrin $(2013 ; 2019 a, b)$ and supports the hypothesis that women behavior is at the chore of the demographic transition. It suggests that the more women are educated today, the fewer children they have tomorrow. Table 9 shows particularly strong results for all specifications (at 0.1\%). Contrary to what found by Galloway et al. (1998) and Becker et al. (2010), our coefficients do not indicate that the fertility transition is stronger in urbanized area. Contrary also to the results found on the short-run, the coefficients indicate that the fertility transition is stronger in areas where individuals are more oriented toward agriculture. ${ }^{13}$ Similarly, the transition is also stronger in areas with a higher share of Protestants. In the complete specification reported in model 4 (Table 9), we observe that an increase in the variation of the female literacy rate by $10 \%$ is likely to decrease the variation of the birth rate by 2.3 percentage point. In terms of explanatory power, the richest model (column 10 to 12 - Table 9) accounts for more than $50 \%$ of the variation across counties of the variations in the crude birth rate.

\footnotetext{
${ }^{12}$ In order to test the robustness of our results, we add the initial level of birth rate in 1881.

${ }^{13}$ Note that agricultural areas are also those where education levels were historically the lowest and where fertility was the most important (in comparison with industrialized areas).
} 
Table 8: Long-run results for education and fertility: Men

\begin{tabular}{|c|c|c|c|c|c|c|c|c|c|c|c|c|}
\hline & \multicolumn{12}{|c|}{$\begin{array}{l}\text { Dependent Variable Crude Birth Rate (\% change } \\
\text { 1881-1911) }\end{array}$} \\
\hline & \multicolumn{3}{|l|}{ (1) } & \multicolumn{3}{|l|}{ (2) } & \multicolumn{3}{|l|}{ (3) } & \multicolumn{3}{|l|}{ (4) } \\
\hline & $\tau=0.25$ & $\tau=0.50$ & $\tau=0.75$ & $\tau=0.25$ & $\tau=0.50$ & $\tau=0.75$ & $\tau=0.25$ & $\tau=0.50$ & $\tau=0.75$ & $\tau=0.25$ & $\tau=0.50$ & $\tau=0.75$ \\
\hline Male literacy & -0.028 & $-0.274 *$ & $-0.252 *$ & -0.061 & $-0.301 *$ & $-0.271 *$ & -0.063 & $-0.305^{*}$ & -0.087 & -0.075 & -0.204 & -0.002 \\
\hline (\% change 1856-70) & $(0.149)$ & $(0.157)$ & $(0.152)$ & $(0.150)$ & (0.159) & $(0.156)$ & $(0.151)$ & $(0.160)$ & $(0.160)$ & $(0.167)$ & $(0.167)$ & $(0.162)$ \\
\hline \multirow[t]{2}{*}{ Crude birth rate 1851} & $-0.019 * * *$ & $-0.017^{* * *}$ & $-0.014 * * *$ & $-0.018 * * *$ & $-0.016^{* * *}$ & $-0.013 * * *$ & $-0.017 * *$ & $-0.013 * * *$ & $-0.103 * *$ & $-0.016 * * *$ & $-0.024 * * *$ & $-0.020 * * *$ \\
\hline & $(0.004)$ & $(0.004)$ & $(0.003)$ & $(0.004)$ & $(0.004)$ & $(0.003)$ & $(0.005)$ & $(0.004)$ & $(0.004)$ & $(0.008)$ & $(0.006)$ & $(0.005)$ \\
\hline \multirow[t]{2}{*}{ Male in agriculture } & $-0.231 *$ & $-0.210 * *$ & $-0.194 * *$ & $-0.220 *$ & $-0.201 *$ & $-0.188^{*}$ & $-0.221 *$ & $-0.203^{*}$ & $-0.185^{*}$ & $-0.213^{*}$ & $-0.266 * *$ & $-0.238 * *$ \\
\hline & $(0.124)$ & $(0.107)$ & $(0.098)$ & $(0.126)$ & $(0.108)$ & $(0.098)$ & $(0.128)$ & $(0.107)$ & $(0.098)$ & $(0.131)$ & $(0.114)$ & $(0.102)$ \\
\hline \multirow[t]{2}{*}{ Male in industry } & -0.088 & 0.148 & $0.297^{*}$ & -0.091 & 0.145 & $0.296^{*}$ & -0.080 & 0.174 & $0.702 * * *$ & -0.071 & 0.101 & $0.639 * * *$ \\
\hline & $(0.276)$ & $(0.185)$ & $(0.161)$ & $(0.283)$ & $(0.187)$ & $(0.162)$ & $(0.289)$ & $(0.210)$ & $(0.142)$ & $(0.294)$ & (0.193) & $(0.128)$ \\
\hline \multirow[t]{2}{*}{ Urbanization } & -0.620 & -1.880 & $-2.487^{*}$ & -0.505 & -1.784 & $-2.422 *$ & -0.512 & -1.803 & -1.032 & -0.538 & -1.585 & -0.844 \\
\hline & (1.464) & (1.387) & $(1.311)$ & (1.491) & (1.388) & $(1.312)$ & (1.517) & (1.141) & $(0.878)$ & $(1.540)$ & $(1.235)$ & $(0.893)$ \\
\hline \multirow[t]{2}{*}{ Population density } & -0.004 & 0.045 & 0.058 & -0.009 & 0.041 & 0.056 & -0.011 & 0.036 & -0.036 & -0.006 & 0.001 & -0.066 \\
\hline & (0.114) & $(0.113)$ & $(0.100)$ & $(0.114)$ & $(0.113)$ & $(0.100)$ & $(0.114)$ & $(0.114)$ & $(0.075)$ & $(0.122)$ & $(0.092)$ & $(0.057)$ \\
\hline \multirow[t]{2}{*}{ Share Protestants } & & & & -0.002 & -0.002 & -0.001 & -0.002 & -0.002 & -0.002 & -0.002 & -0.003 & -0.003 \\
\hline & & & & $(0.002)$ & $(0.002)$ & $(0.002)$ & $(0.002)$ & $(0.002)$ & $(0.002)$ & $(0.002)$ & $(0.002)$ & $(0.003)$ \\
\hline \multirow[t]{2}{*}{ Life expectancy } & & & & & & & 0.001 & 0.004 & $0.008^{*}$ & 0.001 & 0.006 & $0.010 * *$ \\
\hline & & & & & & & $(0.005)$ & $(0.005)$ & $(0.004)$ & $(0.005)$ & $(0.004)$ & $(0.004)$ \\
\hline \multirow[t]{2}{*}{ Crude birth rate 1881} & & & & & & & & & & -0.001 & $0.015^{* *}$ & $0.013^{* *}$ \\
\hline & & & & & & & & & & $(0.005)$ & $(0.007)$ & $(0.006)$ \\
\hline \multirow[t]{2}{*}{ Constant } & $0.419 * * *$ & $0.411^{* * *}$ & $0.338 * *$ & $0.404 * *$ & $0.398 * * *$ & $0.330 * *$ & $0.317^{* *}$ & 0.157 & 0.537 & $0.329 * *$ & $0.574 * * *$ & $0.139 * *$ \\
\hline & $(0.122)$ & $(0.113)$ & $(0.110)$ & $(0.126)$ & $(0.115)$ & $(0.110)$ & $(0.156)$ & $(0.306)$ & $(0.277)$ & $(0.139)$ & $(0.119)$ & $(0.062)$ \\
\hline $\mathrm{N}$ & 82 & 82 & 82 & 82 & 82 & 82 & 82 & 82 & 82 & 82 & 82 & 82 \\
\hline $\mathrm{R}^{2}$ & 0.341 & 0.391 & 0.369 & 0.347 & 0.396 & 0.372 & 0.348 & 0.400 & 0.420 & 0.349 & 0.462 & 0.456 \\
\hline $\mathrm{F}$ & $7.61 * * *$ & $15.27^{* * *}$ & $14.64 * * *$ & $7.65 * * *$ & $14.81 * * *$ & $12.45^{* * *}$ & $6.42 * * *$ & $12.56^{* * *}$ & $11.04^{* * *}$ & $5.83 * * *$ & $14.09 * * *$ & $11.43^{* * *}$ \\
\hline
\end{tabular}

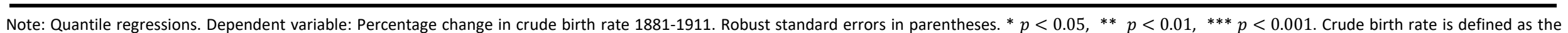
number of birth (in $1000 \mathrm{~s}$ ) over the total population. Male literacy rate is the percentage change in the share of who signed their wedding contract between 1856 and 1870.

Source: County-level data from the Statistique Générale de la France. 
Table 9: Long-run results for education and fertility: Women

\begin{tabular}{|c|c|c|c|c|c|c|c|c|c|c|c|c|}
\hline \multirow{3}{*}{ Dependent Variable } & \multicolumn{12}{|c|}{ Crude Birth Rate (\% change 1881-1911) } \\
\hline & \multicolumn{3}{|l|}{ (1) } & \multicolumn{3}{|l|}{$(2)$} & \multicolumn{3}{|l|}{ (3) } & \multicolumn{3}{|l|}{ (4) } \\
\hline & $\tau=0.25$ & $\tau=0.50$ & $\tau=0.75$ & $\tau=0.25$ & $\tau=0.50$ & $\tau=0.75$ & $\tau=0.25$ & $\tau=0.50$ & $\tau=0.75$ & $\tau=0.25$ & $\tau=0.50$ & $\tau=0.75$ \\
\hline Female literacy & $-0.164 * * *$ & $-0.272 * * *$ & $-0.164 * * *$ & $-0.223 * *$ & $-0.270 * * *$ & $-0.160 * *$ & $-0.165^{* *}$ & $-0.262 * * *$ & $-0.154 * *$ & $-0.230 * * *$ & $-0.233 * * *$ & $-0.122 *$ \\
\hline (\% change 1856-70) & $(0.027)$ & $(0.061)$ & $(0.068)$ & $(0.069)$ & $(0.061)$ & $(0.079)$ & $(0.076)$ & $(0.059)$ & $(0.066)$ & $(0.071)$ & $(0.056)$ & $(0.070)$ \\
\hline \multirow[t]{2}{*}{ Crude birth rate 1851} & $-0.156 * * *$ & $-0.015 * * *$ & $-0.013 * * *$ & $-0.016 * * *$ & $-0.015^{* * *}$ & $-0.015 * * *$ & $-0.011 *$ & $-0.011 * * *$ & $-0.008 * *$ & $-0.012 *$ & $-0.021 * * *$ & $-0.017 * * *$ \\
\hline & $(0.003)$ & $(0.003)$ & $(0.003)$ & $(0.004)$ & $(0.003)$ & $(0.003)$ & $(0.006)$ & $(0.004)$ & $(0.003)$ & $(0.007)$ & $(0.005)$ & $(0.005)$ \\
\hline \multirow[t]{2}{*}{ Female in agriculture } & $-0.240 * *$ & $-0.131^{*}$ & $-0.221 * *$ & -0.135 & $-0.132 *$ & $-0.241 * *$ & 0.050 & -0.127 & $-0.216 * *$ & -0.123 & $-0.163^{*}$ & $-0.266 * * *$ \\
\hline & $(0.075)$ & $(0.078)$ & $(0.074)$ & $(0.101)$ & $(0.079)$ & $(0.076)$ & $(0.101)$ & $(0.079)$ & $(0.075)$ & $(0.101)$ & $(0.088)$ & $(0.077)$ \\
\hline \multirow[t]{2}{*}{ Female in industry } & $0.578 * * *$ & 0.002 & 0.236 & -0.125 & 0.011 & $0.598 * * *$ & -0.057 & 0.070 & $0.310^{*}$ & -0.096 & 0.027 & $0.646 * * *$ \\
\hline & $(0.156)$ & $(0.206)$ & $(0.166)$ & $(0.306)$ & $(0.205)$ & $(0.158)$ & $(0.272)$ & $(0.218)$ & $(0.177)$ & $(0.315)$ & $(0.213)$ & $(0.156)$ \\
\hline \multirow[t]{2}{*}{ Urbanization } & -1.303 & -1.582 & $-2.358 * *$ & -0.289 & -1.505 & -1.121 & 1.544 & -1.289 & $-2.049 *$ & -0.333 & -0.973 & -0.527 \\
\hline & $(0.889)$ & $(1.122)$ & $(1.134)$ & $(1.281)$ & $(1.126)$ & $(0.886)$ & $(1.245)$ & $(1.186)$ & $(1.113)$ & $(1.364)$ & $(1.095)$ & $(0.800)$ \\
\hline \multirow[t]{2}{*}{ Population density } & -0.035 & 0.034 & 0.035 & -0.028 & 0.028 & -0.049 & -0.026 & 0.012 & 0.011 & -0.0224 & -0.019 & -0.101 \\
\hline & $(0.084)$ & $(0.093)$ & $(0.087)$ & (0.099) & $(0.094)$ & $(0.085)$ & $(0.109)$ & $(0.095)$ & $(0.086)$ & $(0.111)$ & $(0.074)$ & $(0.063)$ \\
\hline \multirow[t]{2}{*}{ Share Protestants } & & & & -0.003 & -0.001 & $-0.003^{*}$ & $-0.005 * *$ & -0.001 & -0.0008 & -0.002 & -0.002 & $-0.004 * *$ \\
\hline & & & & $(0.002)$ & $(0.001)$ & $(0.002)$ & $(0.002)$ & $(0.001)$ & $(0.002)$ & $(0.002)$ & $(0.002)$ & $(0.002)$ \\
\hline \multirow[t]{2}{*}{ Life expectancy } & & & & & & & 0.004 & 0.005 & $0.005^{*}$ & 0.007 & $0.007^{*}$ & $0.009 * *$ \\
\hline & & & & & & & $(0.005)$ & $(0.004)$ & $(0.003)$ & $(0.004)$ & $(0.003)$ & $(0.003)$ \\
\hline \multirow[t]{2}{*}{ Crude birth rate 1881} & & & & & & & & & & -0.004 & $0.014^{* *}$ & $0.013 * * *$ \\
\hline & & & & & & & & & & $(0.006)$ & $(0.006)$ & $(0.005)$ \\
\hline \multirow[t]{2}{*}{ Constant } & $0.481 * * *$ & $0.348 * *$ & $0.354 * * *$ & $0.325 * * *$ & $0.346 * *$ & $0.478 * * *$ & $0.185^{* *}$ & $0.128 * *$ & $0.208^{* *}$ & $0.276 * *$ & $0.112 * * *$ & 0.116 \\
\hline & $(0.122)$ & $(0.106)$ & $(0.099)$ & $(0.123)$ & $(0.107)$ & $(0.122)$ & $(0.892)$ & $(0.062)$ & $(0.098)$ & $(0.101)$ & $(0.005)$ & $(0.005)$ \\
\hline $\mathrm{N}$ & 82 & 82 & 82 & 82 & 82 & 82 & 82 & 82 & 82 & 82 & 82 & 82 \\
\hline $\mathrm{R}^{2}$ & 0.418 & 0.466 & 0.404 & 0.418 & 0.468 & 0.429 & 0.379 & 0.481 & 0.423 & 0.425 & 0.535 & 0.489 \\
\hline $\mathrm{F}$ & $5.61 * * *$ & $23.79 * * *$ & $14.75^{* * *}$ & $12.48 * * *$ & $23.92 * * *$ & $11.56 * * *$ & $5.96 * * *$ & $23.10 * * *$ & $12.14^{* * *}$ & $9.071 * * *$ & $17.91 * * *$ & $9.097 * * *$ \\
\hline
\end{tabular}

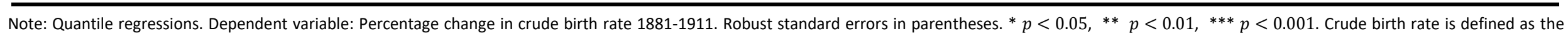

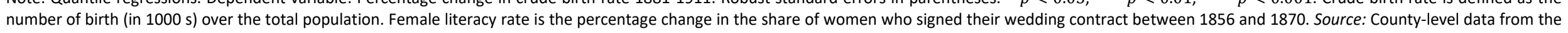
Statistique Générale de la France. 
In Figures 4 to 6, we have graphically presented full distributional effects of education on fertility transitions. For instance, Figure 5 (containing four graphs) presents how a small change in educational levels for both male and female affects the rate of fertility transition. In these figures, we have only reported $10^{\text {th }}, 50^{\text {th }}$ and $90^{\text {th }}$ quantile estimates along with the OLS lines. The blue lines in each graph present the $10^{\text {th }}$ quantile estimates, whereas the green lines represent $90^{\text {th }}$ quantile. Broken red lines are OLS estimates, whereas thick purple lines are median quantile estimates. It is clear from the four graphs that changes in educational status had discernible effects on fertility transition and that there is clear gender-bias in the estimated effects. To focus on this point, we have additionally estimated the partial effect of education on fertility transition for both men and women. The partial effect at each quantile is given by the formula $\frac{\partial Q_{t}\left(F_{i} \mid E_{i}\right)}{\partial E_{i}}$ where $i=\{$ Male, Female $\}$. Table 10 presents the estimates of these effects based on Tables 4 and 5 (for short-run) and Tables 8 and 9 for long-run. It is clear from the estimates in Table 10 that the magnitude of a decline in fertility in female population is larger than men for all quantiles in the long-run and all quantiles (except $25^{\text {th }}$ ) for short-run. Our inter-quantile difference test (F-test values) also point at the significance of difference in results across quantiles.

Table 10: Comparison of Partial Effects

\begin{tabular}{lllll}
\hline & \multicolumn{3}{l}{ Short-run } & \multicolumn{3}{l}{ Long-run } \\
\cline { 2 - 4 } & Boys & Girls & Boys & Girls \\
\hline \multirow{2}{*}{$25^{\text {th }}$ Quantile } & -6.677 & -5.736 & -0.075 & -0.230 \\
$50^{\text {th }}$ Quantile & -6.745 & -8.859 & -0.204 & -0.233 \\
$75^{\text {th }}$ Quantile & -7.859 & -9.572 & -0.002 & -0.122 \\
& & & & \\
\hline Inter-quantile difference & $\mathrm{F}(2,81)=7.352$ & $\mathrm{~F}(2,81)=9.695$ & $\mathrm{~F}(2,80)=6.109$ & $\mathrm{~F}(2,80)=7.398$ \\
test & $(p=0.008)$ & $(p=0.006)$ & $(p=0.004)$ & $(p=0.004)$ \\
\hline
\end{tabular}

Overall, our results indicate that the variations in female endowment in human capital have a robust and significant impact on the fertility transition contrary to male endowment in human capital. This result is consistent with the intuition of the unified growth model of Diebolt and Perrin (2019a) briefly presented in Section 1.2, according to which female endowed with a higher amount of human capital tend to limit their fertility due to a larger 
opportunity cost of having children than female endowed with lower amount of human capital.

\section{Figure 4: Effect of education on fertility (short-run)}

(a) Male

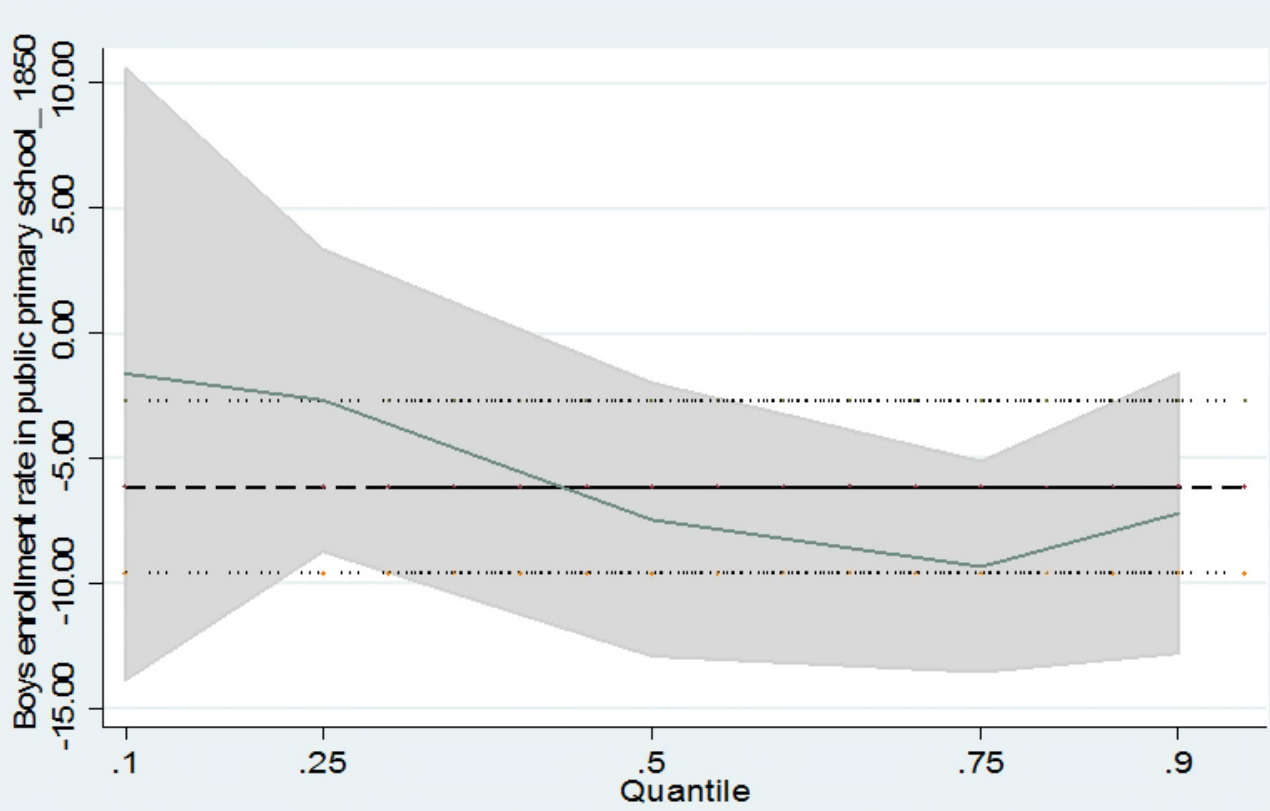

(b) Female

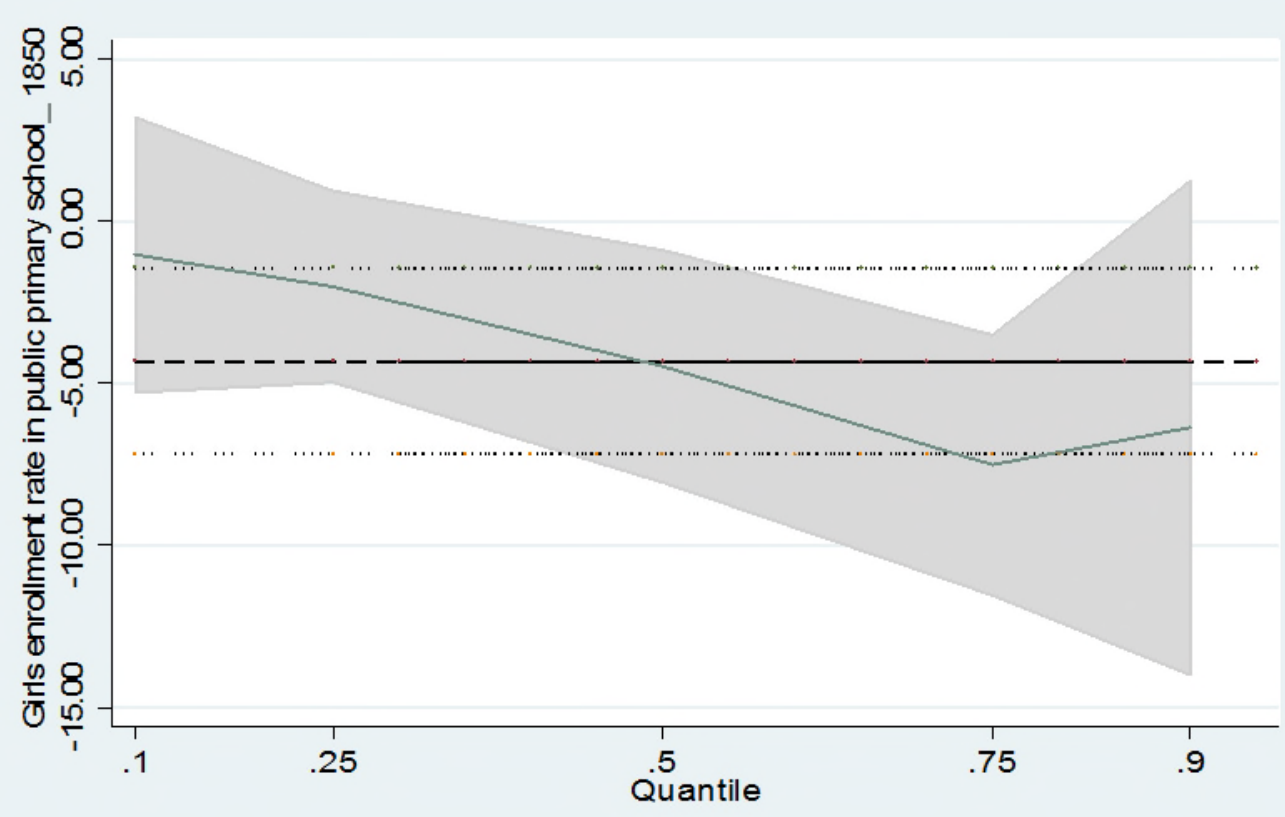


Figure 5: Variation in female education and fertility relationship at various quantiles

(a) Male

Effect of male education on fertility transition

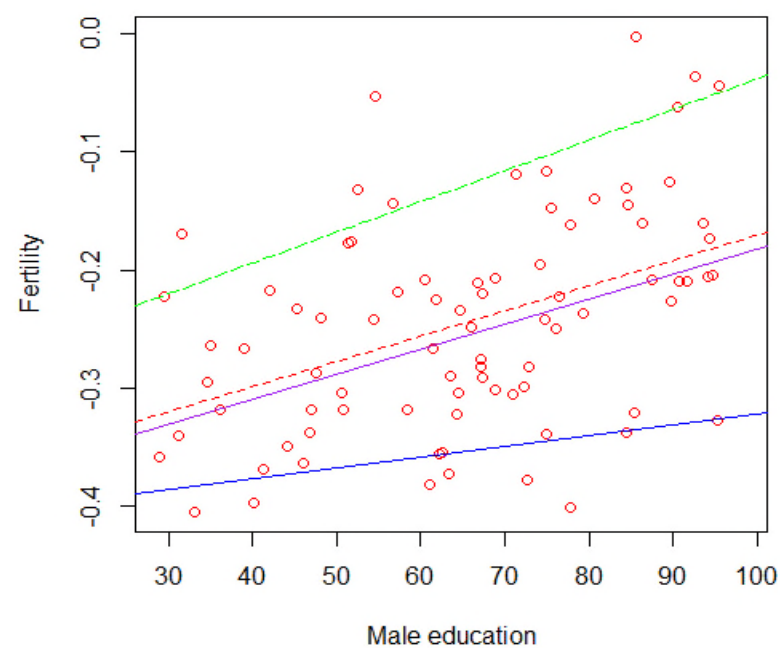

(c) Male

Effect of male education on change in fertility

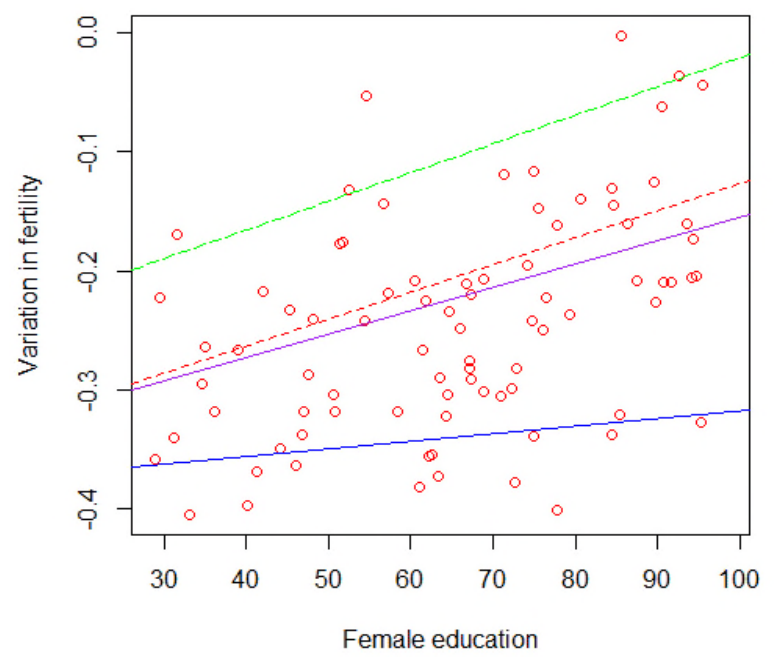

(b) Female

Effect of female education on fertility transition

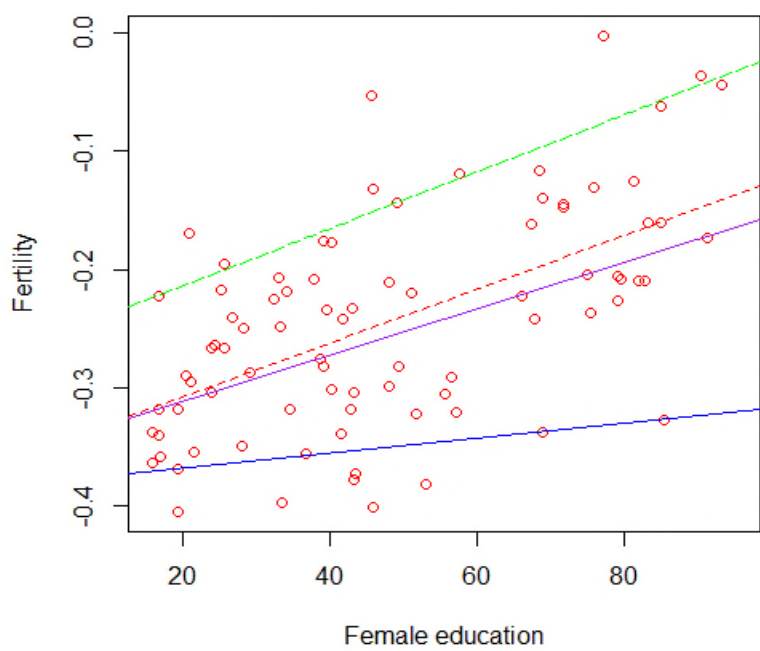

(d) Female

Fertility and female education relationship

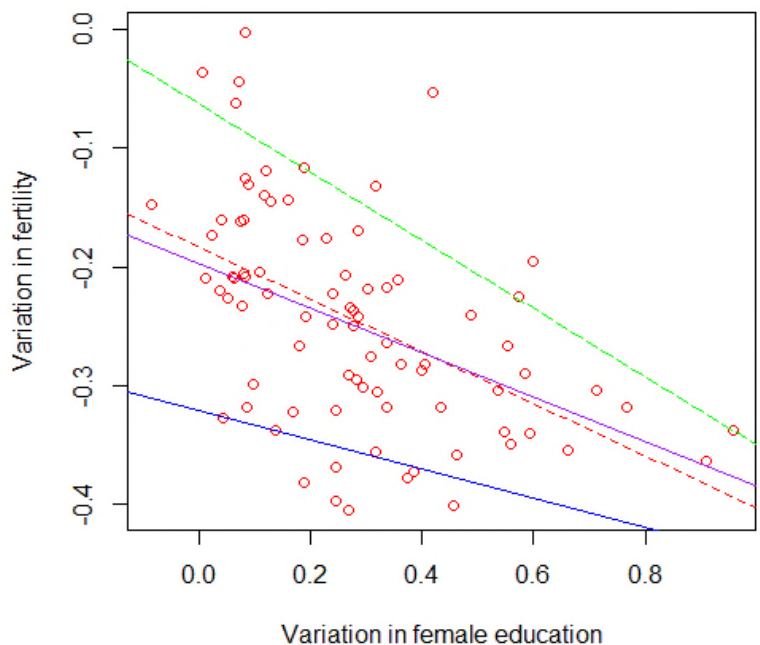


Figure 6: Effect of male human capital on fertility transition: IV Quantile Regression

(a) Male

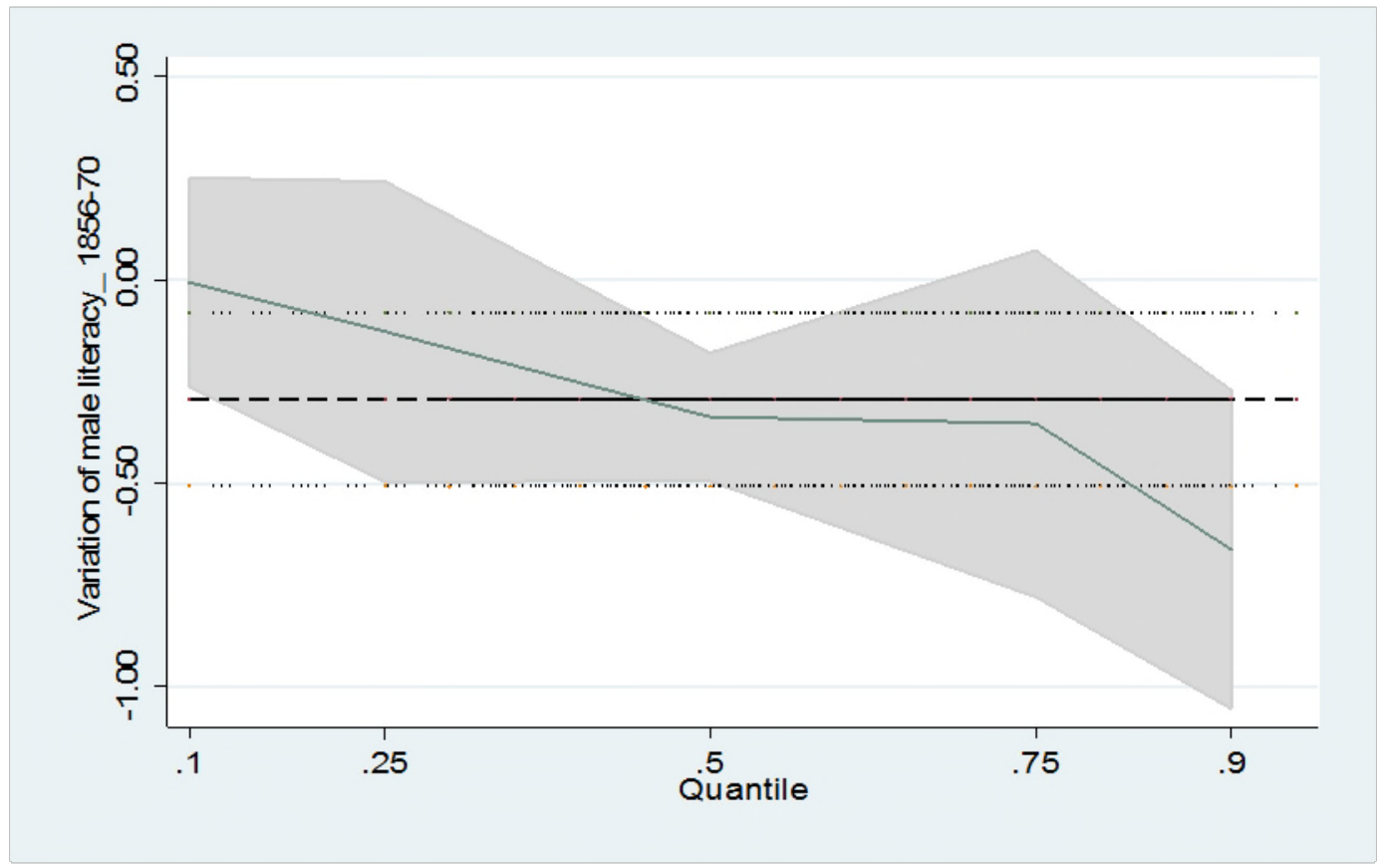

(b) Female

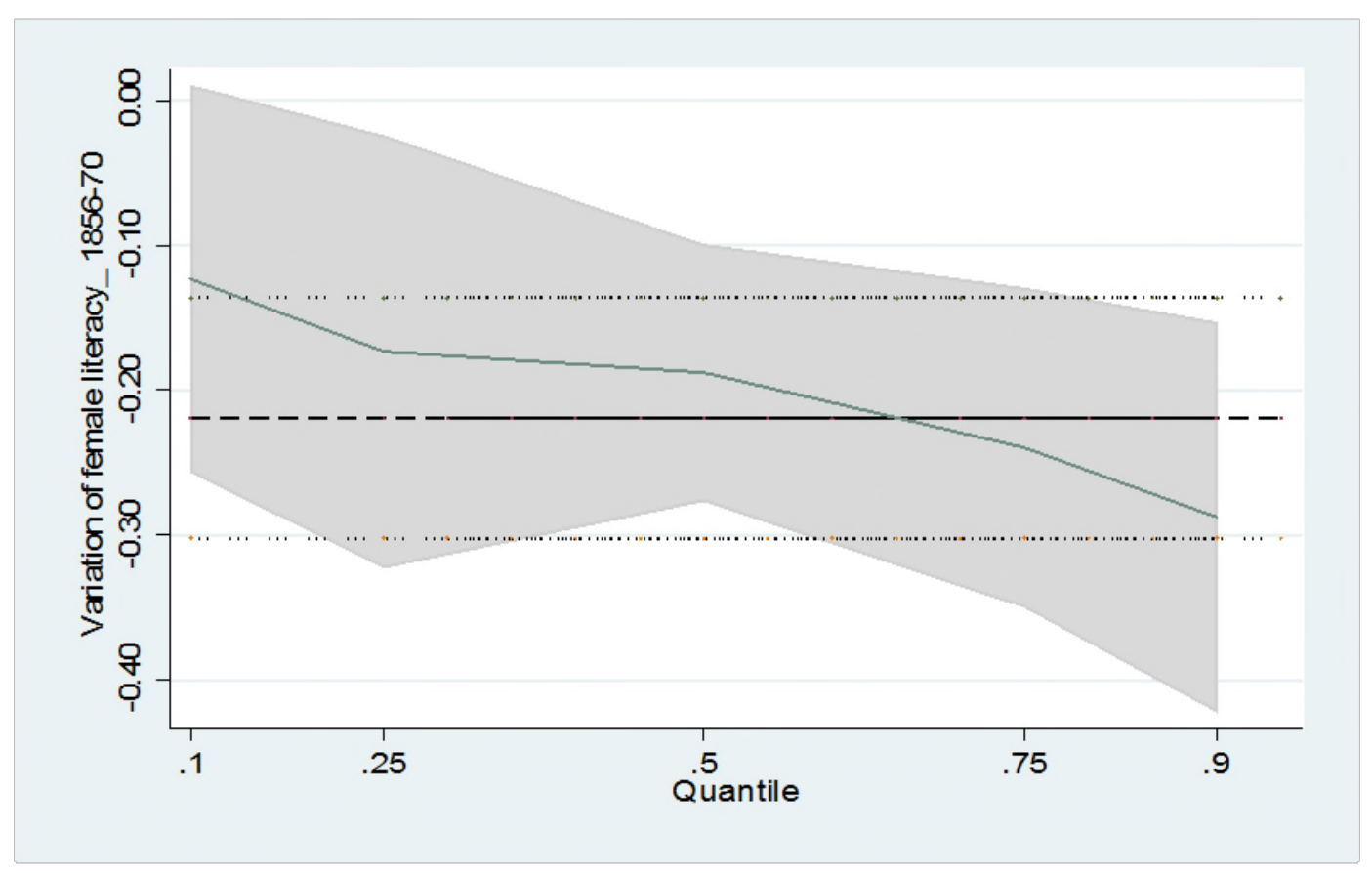




\subsection{Robustness}

An additional exercise is to check if our findings of a quantity-quality trade-off, especially the instrumental role of female empowerment are sensitive to the addition of control variables and/or the introduction of alternative dependent variables. As a first step towards achieving this aim, we have re-estimated the education-fertility channel by replacing first the dependent variable. Accordingly, we have replaced crude birth rate with marital fertility rate. Our second strategy is to retain the original dependent variable, crude birth rate but add extra control variables, such as infant mortality, child mortality, male and female wages in agriculture in 1852. Table 11 reports these results. Instead of estimating each set of equations, we have only presented the estimation results for the full model for both men and women. Model 1 reports the results with respect to a change of the dependent variable in the female and male estimations. Model 2 reports the results with additional control variables.

As such, changing dependent variable does not alter our main finding of a negative relationship between fertility and education, although the results appear weaker in magnitudes at low and high quantiles than the one we observed when using the crude birth rate as dependent variable. Moreover, other control variables in this regression setting also present weaker results despite the fact that population density, for instance, indicate negative effect (although insignificant), whereas the positive impact of urbanization is perceived at lower quantile (in case of women). Life-expectancy, as earlier, is significantly negative and indicates that in the face of fertility, reducing effect of life-expectancy, enhancing education reduced fertility. This result is more acute at the lower quantile for women. When we add more control variables, while maintaining crude birth rate as the main dependent variable, the strategy does not improve the results much. The insignificance and weaker results for the effect of education on fertility seem to have been overweighed by likely correlation between these additional variables with education. Instrumentation did not help much. Therefore, this robustness exercise, while pointing at the capital importance of crude birth rate and marital fertility rate as relevant variables for quantity-quality tradeoff, need to be pursued with caution concerning the choice of other variables. 
Table 11: Robustness of estimates - education and fertility channel: Men and Women

\begin{tabular}{|c|c|c|c|c|c|c|c|c|c|c|c|c|}
\hline \multirow{3}{*}{ Dependent Variable } & \multicolumn{6}{|l|}{ Men } & \multicolumn{6}{|l|}{ Women } \\
\hline & (1) MFR & & & (2) CBR & & & (1) MFR & & & (2) CBR & & \\
\hline & $\tau=0.25$ & $\tau=0.50$ & $\tau=0.75$ & $\tau=0.25$ & $\tau=0.50$ & $\tau=0.75$ & $\tau=0.25$ & $\tau=0.50$ & $\tau=0.75$ & $\tau=0.25$ & $\tau=0.50$ & $\tau=0.75$ \\
\hline \multirow[t]{2}{*}{ Enrollment } & $-0.098^{* *}$ & $-0.446^{*}$ & $-0.422 * * *$ & -0.009 & $-0.112^{*}$ & -0.088 & $-0.159 * * *$ & $-0.432 * * *$ & $-0.560 * * *$ & -0.012 & $-0.127^{*}$ & -0.089 \\
\hline & $(0.003)$ & $(0.230)$ & $(0.003)$ & $(0.008)$ & $(0.642)$ & $(0.007)$ & $(0.002)$ & $(0.002)$ & $(0.003)$ & $(0.007)$ & $(0.599)$ & $(0.007)$ \\
\hline \multirow[t]{2}{*}{ Employ. in agriculture } & 0.522 & -0.133 & 0.541 & 0.535 & -0.129 & 0.512 & 0.265 & 0.225 & 0.061 & 0.535 & -0.157 & 0.512 \\
\hline & $(0.376)$ & $(0.201)$ & $(0.534)$ & $(0.465)$ & $(0.206)$ & $(0.522)$ & $(0.418)$ & $(0.390)$ & $(0.440)$ & $(0.465)$ & $(0.206)$ & $(0.522)$ \\
\hline \multirow[t]{2}{*}{ Employ. in industry } & $-1.296 * * *$ & 0.319 & 0.330 & -0.971 & -0.878 & 0.371 & $-1.535^{*}$ & -1.069 & -1.307 & -0.971 & -0.699 & 0.371 \\
\hline & $(0.349)$ & $(0.602)$ & $(0.893)$ & $(1.104)$ & $(0.734)$ & $(0.798)$ & $(0.933)$ & $(0.874)$ & $(0.984)$ & $(1.104)$ & $(0.505)$ & $(0.798)$ \\
\hline \multirow[t]{2}{*}{ Urbanization } & 3.477 & 3.096 & 2.531 & 8.464 & $12.98 * * *$ & $26.411^{* * *}$ & $9.159 * *$ & 6.149 & 3.819 & 8.464 & $14.97 * * *$ & $26.411 * * *$ \\
\hline & (5.916) & $(2.553)$ & (2.087) & $(5.477)$ & (2.082) & (9.945) & $(4.795)$ & $(4.475))$ & $(5.055)$ & $(5.477)$ & $(3.860)$ & (9.945) \\
\hline \multirow[t]{2}{*}{ Population density } & -0.124 & -0.078 & -0.130 & -0.211 & $-1.171^{* *}$ & $-0.615 * *$ & $-0.261^{* *}$ & $-0.195 * *$ & -0.151 & -0.211 & $-0.985^{* *}$ & $-0.615 * *$ \\
\hline & $(0.132)$ & $(0.131)$ & $(0.114)$ & $(0.235)$ & $(0.268)$ & $(0.217)$ & $(0.108)$ & $(0.101)$ & $(0.114)$ & $(0.235)$ & $(0.342)$ & $(0.217)$ \\
\hline \multirow[t]{2}{*}{ Share Protestants } & $0.012^{*}$ & 0.007 & $0.037 * * *$ & $0.010^{*}$ & 0.005 & 0.023 & 0.020 & $0.034 * *$ & $0.037 * * *$ & $0.009 *$ & 0.004 & 0.023 \\
\hline & $(0.005)$ & $(0.005)$ & $(0.012)$ & $(0.015)$ & $(0.005)$ & $(0.012)$ & $(0.023)$ & $(0.011)$ & $(0.012)$ & $(0.015)$ & $(0.005)$ & $(0.012)$ \\
\hline \multirow[t]{2}{*}{ Life expectancy } & $-0.065 * * *$ & 0.0009 & $-0.099 * * *$ & $-0.075 * * *$ & -0.021 & $-0.086 *$ & $-0.072 * * *$ & $-0.057 * * *$ & $-0.053 * * *$ & $-0.078 * * *$ & $-0.088^{*}$ & $-0.086 *$ \\
\hline & $(0.011)$ & $(0.008)$ & $(0.015)$ & $(0.013)$ & $(0.045)$ & $(0.049)$ & $(0.014)$ & $(0.013)$ & $(0.015)$ & $(0.013)$ & $(0.038)$ & $(0.049)$ \\
\hline \multirow[t]{2}{*}{ Child mortality } & & & & 15.658 & 25.145 & 28.517 & & & & 17.398 & 29.233 & 28.517 \\
\hline & & & & $(13.218)$ & $(17.167)$ & $(18.888)$ & & & & $(13.666)$ & $(18.260)$ & $(18.888)$ \\
\hline \multirow[t]{2}{*}{ Wage in agriculture } & & & & $-0.702 * * *$ & -0.686 & -0.056 & & & & $-0.679 * * *$ & $-0.534^{*}$ & -0.056 \\
\hline & & & & $(0.285)$ & $(0.779)$ & $(0.606)$ & & & & $(0.211)$ & $(0.278)$ & $(0.606)$ \\
\hline \multirow[t]{2}{*}{ School } & & & & -0.285 & -0.554 & $-1.474 * * *$ & & & & -0.305 & -0.634 & $-1.474 * * *$ \\
\hline & & & & $(0.240)$ & $(0.408)$ & $(0.437)$ & & & & $(0.240)$ & $(0.405)$ & $(0.437)$ \\
\hline \multirow[t]{2}{*}{ Constant } & $5.555^{* *}$ & $5.616^{* * *}$ & $7.042 * * *$ & $5.662^{* *}$ & $5.616^{* * *}$ & $10.645^{* * *}$ & $5.719 * * *$ & $5.751 * * *$ & $5.751 * * *$ & $4.981 * * *$ & $4.660 * *$ & $10.645^{* * *}$ \\
\hline & $(0.781)$ & $(0.726)$ & $(0.838)$ & $(1.104)$ & $(0.726)$ & $(2.660)$ & $(0.791)$ & $(0.834)$ & $(0.834)$ & $(1.104)$ & $(2.390)$ & $(2.660)$ \\
\hline $\mathrm{N}$ & 85 & 85 & 85 & 85 & 85 & 85 & 85 & 85 & 85 & 85 & 85 & 85 \\
\hline $\mathrm{R}^{2}$ & 0.406 & 0.454 & 0.454 & 0.267 & 0.483 & 0.502 & 0.421 & 0.409 & 0.409 & 0.450 & 0.493 & 0.522 \\
\hline $\mathrm{F}$ & $63.93 * * *$ & $35.96 * * *$ & $35.96 * * *$ & $4.55^{* *}$ & $14.34 * *$ & $13.83 * * *$ & $13.17^{* * *}$ & $11.27 * * *$ & $11.27^{* * *}$ & $6.38 * *$ & $16.39 * *$ & $18.44^{* * *}$ \\
\hline
\end{tabular}




\section{Conclusion}

This article documents the existence of a quantity-quality trade-off in France during the $19^{\text {th }}$ century. The objective of the article is twofold: (i) investigating both directions of causation of the short-run relationship between education and fertility (i.e. the child quantity-quality trade-off) during the French demographic transition; and (ii) studying the long-term effect of endowment in human capital on the subsequent level of fertility. We contribute to the literature of unified growth theory by shedding light on these two types on relationships from a gendered renewed approach.

Using an original county-level dataset of 86 county observations for the year 1851 built up from the Statistique Générale de la France, we find in Section 3 evidence of the existence of the child quantityquality trade-off during the French demographic transition. This result corroborates the predictions and interpretations of the unified growth literature in line with the seminal work of Galor and Weil (2000).

However, this result may hide a more complex relationship linking education and fertility that is the long-run relationship between the female endowment in human capital and the level of fertility, as predicted by Diebolt and Perrin $(2013,2019 a)$. Hence, using $19^{\text {th }}$ century French data, we have tested in Section 4 the hypothesis that the rise in female endowment in human capital has played a key role in the fertility transition. Our results suggest that women with a higher level of human capital have stronger preferences for a lower number of children. In particular, we find the existence of a negative and significant effect of the variations in female literacy rates (1856-70) on the fertility transition between 1881 and 1911. Counties with higher improvements in female literacy display stronger fertility decline in France at the turn of the $19^{\text {th }}$ century.

From our empirical investigation, we find that the quantity-quality trade-off was possibility driven by women endowment in human capital of the previous generation. By extension, as demographic transition is considered necessary condition to allow economies to move from stagnation to sustained growth, female human capital is likely to be a key ingredient for economic transition. Indeed, female empowerment increases returns to education for girls because of complementarities between technological changes and human capital. Girls invest more in their own education and limit their fertility because of a greater opportunity cost of having children. As a consequence, girls with higher endowments in human capital have fewer children what ultimately leads to the fertility transition. 
Further research needs to extend this case study to wider panel data investigation to confirm the intuition that women may have been an important factor of economic growth in developed countries and may still be in developing areas.

\section{References}

Becker G. S. (1960), An Economic Analysis of Fertility. Demographic and Economic Change in Developed Countries. Princeton, NJ: Princeton University Press.

Becker G. S., H.G. Lewis (1973), "On the Interaction between Quantity and Quality of Children", Journal of Political Economy, 81, pp. S279-S288.

Becker S. O., L. Woessmann (2009), "Was Weber Wrong? A Human Capital Theory of Protestant Economic History", Quarterly Journal of Economics, Vol. 124, pp. 531-596.

Becker S. O., F. Cinnirella, L. Woessmann (2010), "The Trade-off between Fertility and Education: Evidence from before the Demographic Transition", Journal of Economic Growth, Vol. 15, pp. 177-204.

Becker S. O., F. Cinnirella, L. Woessmann (2012), "The effect of investment in children's education on fertility in 1816 Prussia", Cliometrica, Vol. 6, pp. 29-44.

Bignon V., C. García-Peñalosa (2016), "Protectionism and the Education-Fertility Trade-off in Late 19th Century France”, Working Papers halshs-01264614, HAL.

Bonneuil N. (1997), Transformation of the French Demographic Landscape 1806-1906. Oxford: Clarendon Press.

Chesnais J.-C. (1992), The Demographic Transition: Stages, Patterns, and Economic Implications, Oxford: Clarendon Press.

Cinnirella F. (2019), "Marital Fertility and Investment in Children's Education", In: Diebolt C., Rijpma A., Carmichael S., Dilli S., Störmer C. (Eds): Cliometrics of the Family. Springer, Berlin, pp. 33-54.

Clark G., N. Cummins (2016), "The Child Quality-Quantity Tradeoff, England, 1780-1880: A Fundamental Component of the Economic Theory of Growth is missing", CEPR Discussion Paper, No. 11232.

Coale A. J., S. C. Watkins (1986), The Decline of Fertility in Europe. Princeton, NJ: Princeton University Press.

De la Croix D., F. Perrin (2018), "How Far Can Economic Incentives Explain the French Fertility and Education Transition?", European Economic Review, 108, pp. 221-245, 2018.

Diebolt C., A.-R. Menard, F. Perrin (2017), "Behind the fertility-education nexus: what triggered the French development process?”, European Review of Economic History, 21(4), pp. 357-392.

Diebolt C., F. Perrin (2013), "From Stagnation to Sustained Growth: The Role of Female Empowerment", American Economic Review, Vol. 103, pp. 545-549. 
Diebolt C., F. Perrin (2019a), "A Cliometric Model of Unified Growth. Family Organization and Economic Growth in the Long Run of History", in: Diebolt C. et al. (Eds.): Cliometrics of the Family, Springer, Berlin, 2019, pp.7-31.

Diebolt C., F. Perrin (2019b), "Cliometrics of Growth", in: Diebolt C. M. Haupert (Eds.): Handbook of Cliometrics, Springer, Berlin, 2019, pp. 403-421.

Doepke M. (2015), "Gary Becker on the Quantity and Quality of Children", Journal of Demographic Economics, 81(1), pp. 59-66.

Fernihough A. (2017), "Human capital and the Quantity-Quality Trade-off during the Demographic Transition, Journal of Economic Growth, 22, pp. 35-6.5

Galloway P. R., E. A. Hammel, R. D. Lee (1994), "Fertility Decline in Prussia, 1875-1910: A Pooled Cross-Section Time Series Analysis", Population Studies, Vol. 48, pp. 135-158.

Galor O. (2005), "The Demographic Transition and the Emergence of Sustained Economic Growth", Journal of the European Economic Association, Vol. 3, pp. 494-504.

Galor O. (2012), "The Demographic Transition: Causes and Consequences", Cliometrica, Vol. 6, pp. 494-504.

Galor O., O. Moav (2002), "Natural Selection and the Origin of Economic Growth", Quarterly Journal of Economics, Vol. 117, pp. 1133-1191.

Galor O., D. N. Weil (1999), "From Malthusian Stagnation to Modern Growth", American Economic Review, Vol. 89, pp. 150-154.

Galor O., D. N. Weil (2000), "Population, Technology, and Growth: From Malthusian Stagnation to the Demographic Transition and Beyond", American Economic Review, Vol. 90, pp. 806-828.

Hazarika, G., C.K. Jha and S. Sarangi (2019), "Ancestral Ecological Endowments and Missing Women", Journal of Population Economics, 32(4), 1101-1123.

Hartwell, C.A. (2019), "Short waves in Hungary, 1923 and 1946: Persistence, chaos, and (lack of) control", Journal of Economic Behavior \& Organization, 163, 532-550.

Henry L. (1961), “La fécondité naturelle. Observation, théorie, résultats”, Population, Vol 14, pp. 625636.

Klemp M., J. Weisdorf (2019), "Fecundity, Fertility and the Formation of Human Capital", Economic Journal, 129(618), pp. 925-960.

Koenker R. (2005), Quantile regression. Cambridge University Press, Cambridge.

Koenker R., G. Bassett (1978), “Regression quantiles”, Econometrica, Vol. 46, pp. 33-50.

Marchand O., C. Thélot (1997), "Formation de la main d'œuvre et capital humain en France depuis deux siècles", Les Dossiers d'éducation et formation, $\mathrm{n}^{\circ}$ 80, ministère de l'Education Nationale, Direction de l'évaluation de la prospective (DEP), février.

Murphy, T. E. (2015), "Old habits die hard (sometimes)", Journal of Economic Growth, 20(2), pp. 177222. 
Perrin, F. (2013), Gender Equality and Economic Growth in the Long-Run. A Cliometric Analysis, PhD Dissertation, University of Strasbourg and Sant'Anna School of Advanced Studies. http://www.theses.fr/2013STRAB006

Sánchez-Barricarte J. J. (2001), "A New Proposal for Measuring Marital Fertility in Historical Population", Canadian Studies in Population, Vol. 28, pp. 1-33.

Wooldridge, J. (2002), Econometric Analysis of Cross Section and Panel Data, MIT Press, Cambridge Mass. 


\section{Appendix - County-level Data for France in the $19^{\text {th }}$ Century}

The data used in this article are mainly extracted from books published by the Statistique Générale de la France (SGF) on population, demographic and public education censuses, between 1800 and 1925. Almost all data are available for 86 counties.

Table A: Data Sources and Construction of the Variables

\begin{tabular}{|c|c|c|c|}
\hline Variable & Year & Definition & Source \\
\hline \multicolumn{4}{|l|}{ Education } \\
\hline School enrollment rate & 1850 & $\begin{array}{l}\text { Number of children enrolled in public primary schools } \\
\text { divided by children aged } 6-14\end{array}$ & $\begin{array}{l}\text { Statistique enseignement primaire } \\
\text { and Recensement } 1851\end{array}$ \\
\hline Boys enrollment rate & 1850 & $\begin{array}{l}\text { Number of boys enrolled in public primary schools } \\
\text { divided by boys aged 6-14 }\end{array}$ & $\begin{array}{l}\text { Statistique enseignement primaire } \\
\text { and Recensement } 1851\end{array}$ \\
\hline Girls enrollment rate & 1850 & $\begin{array}{l}\text { Number of girls enrolled in public primary schools } \\
\text { divided by girls aged } 6-14\end{array}$ & $\begin{array}{l}\text { Statistique enseignement primaire } \\
\text { and Recensement } 1851\end{array}$ \\
\hline Boys schools & 1850 & $\begin{array}{l}\text { Number of public primary schools for boys per } \\
\text { number of boys aged 6-14 }\end{array}$ & $\begin{array}{l}\text { Statistique enseignement primaire } \\
\text { and Recensement } 1851\end{array}$ \\
\hline Girls schools & 1850 & $\begin{array}{l}\text { Number of public primary schools for girls per number } \\
\text { of girls aged } 6-14\end{array}$ & $\begin{array}{l}\text { Statistique enseignement primaire } \\
\text { and Recensement } 1851\end{array}$ \\
\hline Boys enrollment (\% change) & $1861-67$ & $\begin{array}{l}\text { Variation of boys enrollment rate public primary } \\
\text { schools for boys aged 5-15 between } 1850 \text { and } 1867\end{array}$ & $\begin{array}{l}\text { Statistique enseignement primaire } \\
\text { and Recensement 1851, } 1866\end{array}$ \\
\hline Girls enrollment (\% change) & $1851-67$ & $\begin{array}{l}\text { Variation of boys enrollment rate public primary } \\
\text { schools for boys aged 5-15 between } 1850 \text { and } 1867\end{array}$ & $\begin{array}{l}\text { Statistique enseignement primaire } \\
\text { and Recensement 1851, } 1866\end{array}$ \\
\hline Male literacy (\% change) & $1856-70$ & $\begin{array}{l}\text { Variation of the share of men who signed their } \\
\text { marriage contract between } 1856 \text { and } 1870\end{array}$ & Statistique enseignement primaire \\
\hline Female literacy (\% change) & $1856-70$ & $\begin{array}{l}\text { Variation of the share of female who signed their } \\
\text { marriage contract between } 1856 \text { and } 1870\end{array}$ & Statistique enseignement primaire \\
\hline Distance to Mainz & --- & $\begin{array}{l}\text { Distance (walk) in km between the main city of the } \\
\text { county and Mainz }\end{array}$ & http://calculerlesdistances.com/ \\
\hline \multicolumn{4}{|l|}{ Fertility } \\
\hline Crude birth rate & 1851 & Number of birth over total population (in thousands) & Recensement 1851 \\
\hline Marital fertility rate & 1851 & $\begin{array}{l}\text { Number of new born per married women in age of } \\
\text { childbearing }(15-45)\end{array}$ & Recensement 1851 \\
\hline Index of marital fertility rate & 1851 & Princeton European Fertility Project & Coale and Watkins (1986) \\
\hline Crude birth rate & 1881 & Number of birth over total population (in thousands) & Recensement 1881 \\
\hline Crude birth rate & $1881-1911$ & $\begin{array}{l}\text { Variation in the crude birth rate between } 1881 \text { and } \\
1911\end{array}$ & Recensement 1881, 1911 \\
\hline Marital fertility rate & $1881-1911$ & $\begin{array}{l}\text { Variation in the marital fertility rate between } 1881 \\
\text { and } 1911\end{array}$ & Recensement 1881, 1911 \\
\hline
\end{tabular}

\section{Economic}

Share in industry

Share in agriculture
Number of people employed in manufacturing pe total population

Number of people working in agriculture per total
Recensement 1851

Recensement 1851 
Male in agriculture

Female in industry

Female in agriculture

Urbanization

Population density

Male wages in agriculture

Female wages in agriculture

1851

1852

1852
Number of men working in agriculture per tota population

Number of women employed in manufacturing per total population

Number of women working in agriculture per total population

Number of towns of more than 2000 inhabitant per $\mathrm{km}^{2}$

Number of people per $\mathrm{km}^{2}$

Average hourly male wages in agriculture
Recensement 1851

Recensement 1851

Recensement 1851

Recensement 1851

Recensement 1851

Recensement 1851

Enquête agricole1852

Enquête agricol 1852

\section{Demographic}

Male life expectancy at age 0

1856

1856

Female life expectancy at age 0

Share married women

Adult sex ratio

Infant mortality

Child mortality
1851

1851

1851
Creation of male life tables using population data

Creation of female life tables using population data

Number of married women per women in age of being married

Number of female aged 15-45 divided by number of male aged 15-45

Mortality quotient at age 0 - Probability to die before celebrating age 5

Mortality quotient at age 5 - Probability to die before celebrating age 10
Recensement 1856

Recensement 1856

Recensement 1851

Recensement 1851

Bonneuil (1997)

Bonneuil (1997)

\section{Socio-economic}

